\title{
Stratigraphie und Morphogenese von frühpleistozänen Ablagerungen zwischen Bodensee und Klettgau
}

\author{
HANS Rudolf GRAF ${ }^{*}$
}

\begin{abstract}
Kurzfassung: Anhand von Feldaufnahmen, sedimentpetrographischen Untersuchungen sowie einer systematischen Auswertung von Literaturangaben und Bohraufnahmen wurde eine Neubearbeitung von Stratigrafie und Paläogeografie der Deckenschotter des Bodensee-Rheingletschersystems im Raum zwischen Bodensee und Schaffhausen sowie im Klettgau vorgenommen.

Es konnten drei morphostratigraphischen Einheiten unterschieden werden: (a) Höhere Deckenschotter, (b) Tiefere Deckenschotter sowie (c) Tiefere Deckenschotter, unteres Niveau. Die Höheren Deckenschotter können lithostratigrafisch nicht weiter gegliedert werden. Die Tieferen Deckenschotter umfassen Ablagerungen aus mindestens zwei kaltzeitlichen Sedimentationsphasen. Es gibt Hinweise, dass zwischen den Sedimentationsphasen temperierte Verhältnisse herrschten. Die jüngste Einheit, „Tieferen Deckenschotter, unteres Niveau“ entstand, nach einer markanten erosiven Umgestaltung des regionalen Entwässerungsnetzes, in einer einzigen Phase.

Eine Analyse der tektonischen Verhältnisse im Untersuchungsgebiet ergab, dass die Höhenlagen der einzelnen Deckenschottervorkommen keine wesentlichen Verfälschungen durch neotektonische Vorgänge aufweisen. Einzig die östlich der Immensee-Verwerfung gelegenen Vorkommen im Hegau könnten eine relative tektonische Verstellung erfahren haben, da sie im Vergleich zu den talwärtigen Korrelaten topographisch ungewöhnlich hoch liegen. Die vorgeschlagene morphostratigraphische Gliederung wird dadurch jedoch nicht in Frage gestellt.

Die Kontrolle des Vorflutniveaus und damit der morphogenetischen Entwicklung des Untersuchungsgebietes erfolgte dominant durch tektonische Vorgänge im Oberrheingrabensystem (Absenkung). Dies gilt auch für die Deckenschotter der zentralen Nordschweiz, weshalb die morphostratigraphischen Einheiten dieser beiden Gebiete miteinander korreliert werden können, wenngleich die Zahl der unterscheidbaren lithostratigraphischen Einheiten nicht übereinstimmt. Für die Höheren Deckenschotter kann das entweder auf eine unvollständige Überlieferung im Untersuchungsgebiet bzw. eine mangelnde Datendichte zurückzuführen sein; es könnte aber auch darauf hindeuten, dass die Verbindung Bodensee-Oberrheingraben später als die Verbindung Walenseetal-Oberrheingraben installiert wurde. Eine Korrelation mit den auf das Donau-System ausgerichteten frühpleistozänen Ablagerungen des süddeutschen Alpenvorlandes ist anhand von morpho- und lithostratigraphischen Kriterien allein nicht möglich.
\end{abstract}

[Stratigraphy and morphogenesis of early pleistocene deposits between Lake Constance und the Klettgau Valley]

\begin{abstract}
The stratigraphy and paleogeography of the Deckenschotter ("cover gravels") of the Rhine glacier system between Lake Constance, the city of Schaffhausen and the Klettgau area (Switzerland, Germany) was revised. This was achieved by means of new surveying and mapping, petrographical analysis und a systematic evaluation of available literature and borehole data.

Within the Deckenschotter three morphostratigraphic units can be discerned: (a) Höhere (higher) Deckenschotter, (b) Tiefere (lower) Deckenschotter and (c) Tiefere Deckenschotter, unteres Niveau (lower level). The topographically highest unit, the Höhere Deckenschotter, cannot be subdivided into lithostratigrafic units. The gravels classified as Tiefere Deckenschotter are grouped into two morphostratigraphical units; the altitude difference of the bases of both units is minor. They are, however, separated by an erosional discontinuity caused by a significant rearrangement of the hydrographic network.
\end{abstract}

\footnotetext{
* Address of author: H. Graf, Dorfstrasse 40, CH-8214 Gächlingen, Schweiz. E-Mail: h.graf@mbn.ch
} 
The older one of the two units (Tiefere Deckenschotter) comprises sediments of at least two depositional phases, separated from each other by a hiatus. There are signs of temperate climatic conditions during the period of non-deposition.

The tectonic analysis of the study area showed that in general the altitude of the Deckenschotter was not affected by post-depositional tectonic activity. A tectonic displacement of the Deckenschotter occurrences in the Hegau cannot be ruled out as their topographic position is unusually high compared to equivalent deposits further paleo-downstream. However, this does not affect the proposed morphostratigraphic subdivision. The Upper Rhine Graben system (tectonic lowering) controlled the hydraulic base level and the morphogenesis for both the Deckenschotter occurrences discussed here and those in central northern Switzerland. Therefore, the morphostratigraphic units of both regions can be correlated, even though the number of lithostratigraphic units does not match. In the Höhere Deckenschotter this could be ascribed to an incomplete sedimentary record or a lack of data; on the other hand, this might indicate that the connection Lake Constance - Upper Rhine Graben was established later than the connection Lake Walen - Upper Rhine Graben. In contrast, there is no simple morpho- or lithostratigrafic correlation with the early pleistocene deposits of the German Alpine Foreland, since they are oriented towards and controlled by the Donau river system.

Keywords: Deckenschotter, morphogenesis, stratigraphy, Switzerland, Baden-Württemberg

\section{Einleitung}

Die frühpleistozänen Ablagerungen im nördlichen Alpenvorland (Süddeutschland, Nordschweiz) finden sich meist im Kuppenbereich von heutigen Hügeln, wo sie von Erosion infolge der sukzessiven Tieferlegung des Entwässerungsnetzes während des mittleren und späten Pleistozäns verschont blieben.

Die frühpleistozänen Schweizerischen Deckenschotter wurden seit Beginn des letzten Jahrhunderts zur Günz- (Höhere / Ältere Deckenschotter) und zur Mindel-Eiszeit (Tiefere/ Jüngere Deckenschotter) gestellt, welche von Penck \& Brückner (1901-1909) im süddeutschen Alpenvorland definiert wurden. Diese Parallelisierung geschah einzig anhand von geomorphologischen Kriterien.

In den 1990-er Jahren wurde für die Deckenschotter der zentralen Nordschweiz, also für das Ausbreitungsbereich des ehemaligen Reussgletscher- sowie des Linth-WalenseeRheingletscher-Systems (Abb. 1), eine weiter gehende Gliederung erarbeitet (GRAF 1993, 2000). Es wurde gezeigt, dass in den untersuchten Deckenschottern häufig eine ,normal-stratigraphische" Überlagerung von verschieden alten glazifluvialen und z.T. glazigenen Ablagerungen vorliegt. So konnte für die Höheren Deckenschotter eine Gliederung in mindestens vier Einheiten (z.B. Irchel ZH, vgl. Abb. 1) und für die Tieferen Deckenschotter eine Dreigliederung (z.B. Iberig AG, vgl. Abb. 1) aufgezeigt werden. Im Rheintal - im Abschnitt zwischen Thur und Aare-Mündung - wurde zusätzlich das Vorkommen einer weiteren, geomorphologisch abgrenzbaren Deckenschottereinheit erkannt (Tiefere Deckenschotter s.l. nach GRAF 1993 bzw. Tiefere Deckenschotter, unteres Niveau nach BitTerLi et al. 2000). Insgesamt kann heute von mindestens acht Deckenschottereinheiten ausgegangen werden, die durchaus jeweils einer separaten Eiszeit zugeschrieben werden können (Abb. 2). Zudem zeigte der Nachweis einer Kleinsäugerfauna auf dem Irchel, welche der stratigraphischen Einheit MN17 zugeordnet werden konnte (ca. 1,8-2,5 Ma BP), dass die Höheren Deckenschotter wesentlich älter sind als bisher angenommen wurde (BOLLIGER et al. 1996).

Die Deckenschottervorkommen zwischen Bodensee und Klettgau (Abb. 1) wurden bisher methodisch nicht in einer Weise untersucht, welche einen einfachen Vergleich mit den Deckenschottern der zentralen Nordschweiz ermöglichen würde. Das Untersuchungsgebiet ist jedoch von großer Bedeutung, indem die hier vorliegenden Deckenschotter für eine mögliche Korrelation der Schweizerischen Deckenschotter mit denjenigen des mittleren und östlichen 


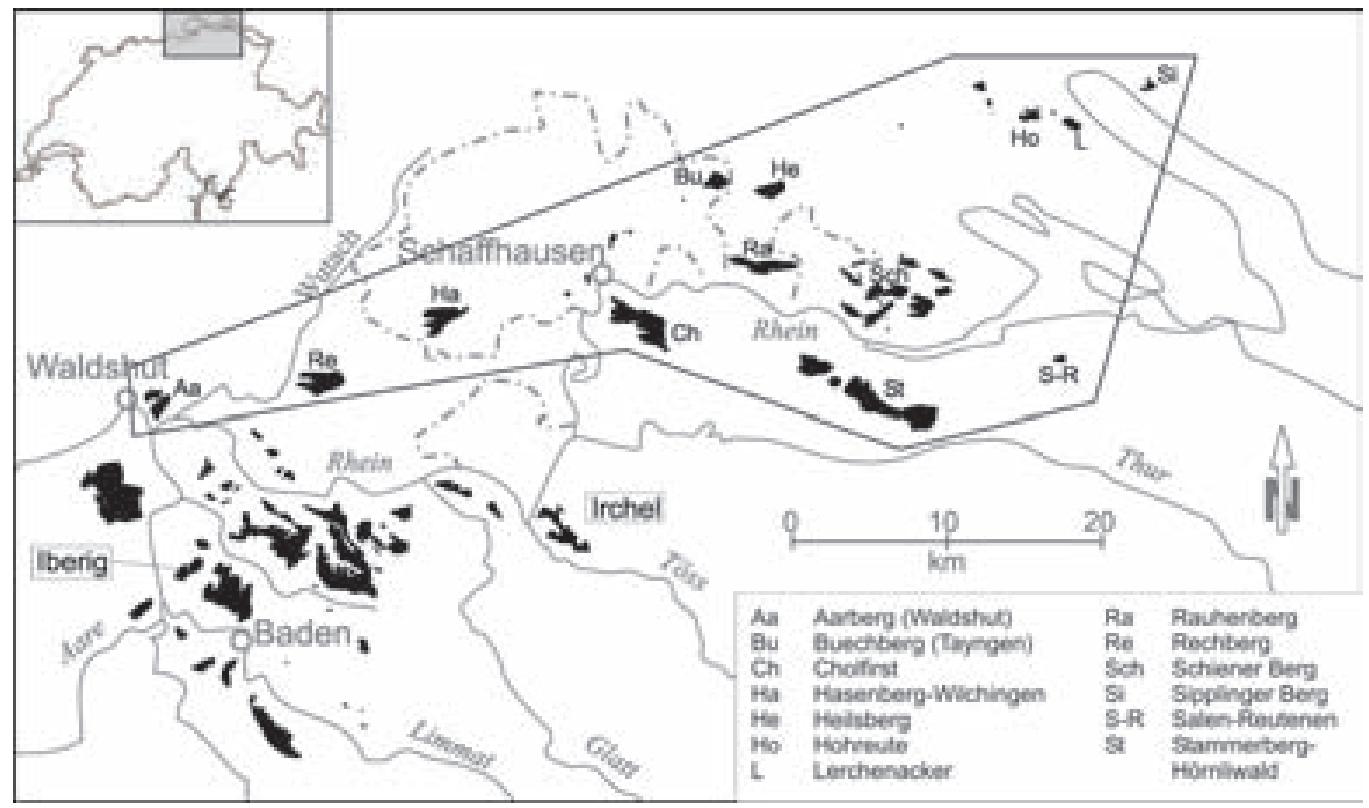

Abb. 1: Untersuchungsgebiet der vorliegenden Arbeit und Verbreitungsgebiet der Deckenschotter in der zentralen Nordschweiz.

Fig. 1: Study area and Deckenschotter occurrences in central northern Switzerland.

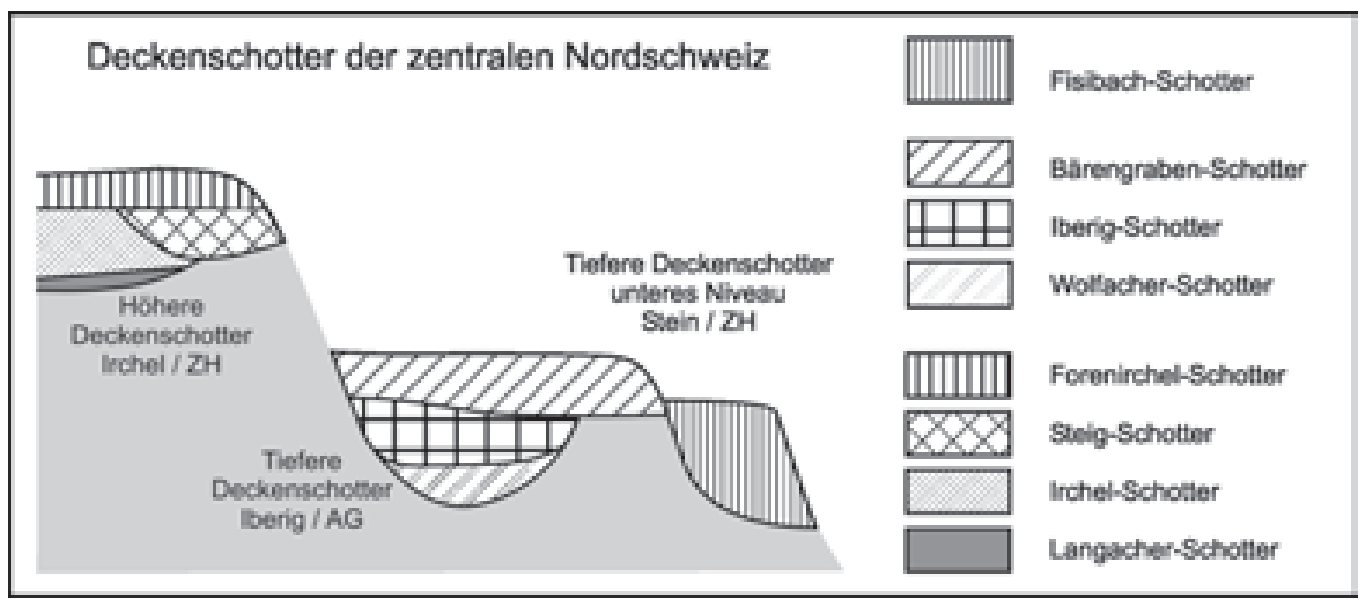

Abb. 2: Aktuelle lithostratigraphische Gliederung der Deckenschotter in der zentralen Nordschweiz (nach GRAF 1993, 2000).

Fig. 2: Current lithostratigraphical subdivision of the Deckenschotter in central northern Switzerland (after GraF 1993, 2000). 
Rheingletschergebietes Deutschlands und damit indirekt mit den weiter östlich gelegenen frühpleistozänen Ablagerungen in Frage kommen.

\section{Sedimentpetrographische Methodik}

\subsection{Geröllzählungen}

Im Untersuchungsgebiet wurden 119 Geröllproben zu je 100 Geröllen entnommen. Die Gerölle wurden zerschlagen und den folgenden 16 Geröllklassen zugeordnet (Zählresultate im Anhang 1):

$\begin{array}{ll}1 & \text { schwarze alpine Kalke } \\ 2 & \text { dunkelgraue alpine Kalke } \\ 3 & \text { alpine Kieselkalke } \\ 4 & \text { übrige alpine Kalke } \\ 5 & \text { Kalke des Juragebirges } \\ 6 & \text { alpine Dolomite } \\ 7 & \text { mürbe Sandsteine } \\ 8 & \text { glimmerreiche Sandsteine } \\ 9 & \text { Gesteine der mittelländischen Molasse } \\ 10 & \text { übrige alpine detritische Gesteine } \\ 11 & \text { Quarzite } \\ 12 & \text { Hornsteine und Radiolarite } \\ 13 & \text { Gangquarze } \\ 14 & \text { übrige magmatische und } \\ & \text { metamorphe Gesteine } \\ 15 & \text { grüne magmatische und } \\ & \text { metamorphe Gesteine } \\ 16 & \begin{array}{l}\text { Marmore, niedriggradige Metapelite } \\ \text { und - psephite (z.T. Grauwacken) }\end{array}\end{array}$

Für das Untersuchungsgebiet hat es sich erwiesen, dass die Art der Probennahme einen sehr großen Einfluss auf die Qualität der Geröllzählungen bzw. deren Vergleichbarkeit untereinander hat. Für eine optimale Probenahme sollte in der Regel eine Sedimentprobe ausgesiebt werden und die Entnahme der benötigten Anzahl Gerölle aus dem Siebgut «blind» erfolgen. Die in der vorliegenden Arbeit untersuchten Sedimente enthalten aber stets (zum Teil grosse Anteile) Dolomitgerölle. Bereits bei relativ wenig fortgeschrittener Verwitterung beginnen diese zu Dolomitasche zu zerfallen. Würde eine solche Probe ausgesiebt, wären die Dolomite wenn nicht völlig verschwunden, so doch sicher in ihrem prozentualen Anteil in der Probe untervertreten. Aus diesem Grund musste die Probenahme für die vorliegende Arbeit «mit offenen Augen» durchgeführt werden, um bei der Materialentnahme auftauchende Dolomitaschenester zu zählen und zu protokollieren. Es hat sich außerdem herausgestellt, dass matrixfreien Schotterpartien (open work gravels) keine Geröllproben entnommen werden dürfen. Solche Proben haben sich jeweils als praktisch dolomitfrei herausgestellt. Dies wahrscheinlich, weil wegen der hohen Porosität und Permeabilität solcher Schotterlagen die zu Asche zerfallenen Dolomite durch Sickerwasser vollständig eliminiert wurden.

\subsection{Schwermineralzählungen}

Es wurden 43 Schwermineralproben aus dem Untersuchungsgebiet untersucht. Die Aufbereitung erfolgte mit 10\%-iger Essigsäure, um den Apatit in den Proben zu erhalten. Die Proben erwiesen sich oft als äußerst reich an Granat (vgl. Zählungen im Anhang 2). Um relevante Angaben über die Verteilung der übrigen Mineralien in der Probe zu erhalten, wurde bei der Auszählung der Proben jeweils 100 Nicht-GranatMineralkörner gezählt und die Zahl der dabei auftretenden Granatkörner gleichzeitig ermittelt.

\subsection{Auswertung der petrographischen Daten}

Die Vergesellschaftung von Gesteins- bzw. Mineralgruppen in einem eiszeitlichen Lockergestein ist Ausdruck einer komplexen Abfolge von Erosions-, Ablagerungs- und Umlagerungsprozessen. Ein beobachtetes Gesteins- (oder Mineral-) Spektrum geht auf eine Mischung von Gesteinen aus verschiedenen Bereichen des Einzugsgebietes z.B. eines Gletschersystems zurück. Ein genetisches, erdgeschichtliches Verständnis von Geröll- oder Mineralvergesellschaftungen kann daher nur erreicht werden, wenn alle enthaltenen Gesteine oder Mineralgruppen berücksichtigt werden.

Das Ziel der statistischen Analyse der für diese Arbeit erhobenen petrographischen Daten war 
das Erkennen der Existenz von verschiedenen Geröll- bzw. Schwermineralfazien und deren Beziehungen untereinander, sowie allenfalls (im lithostratigraphischen Zusammenhang) deren zeitliche Variabilität.

Die Methoden der multivariaten Statistik bieten die Möglichkeit einer objektiven Analyse von grossen Mengen quantitativer Daten, wobei selbst Variablen (Geröllklassen, Schwermineralien) mit generell geringer Individuenzahl berücksichtigt werden. Die Geröll- und Schwermineralzählungen wurden mittels Cluster- und Hauptkomponentenanalysen ausgewertet. Für die nähere Charakterisierung der Methoden sei auf die einschlägige Fachliteratur verwiesen (z.B. Davis 1973, Digby \& Kempton 1982, AitCHISON 1986 usw.). Die Analysen wurden mit dem Programm SYSTAT 8.0 durchgeführt. Als Spezifizierungsparameter der Clusteranalyse wurden Euklidische Distanzen und die ClusterMethode nach WARD (1963) verwendet.

Für die statistische Auswertung der Geröllzählungen wurde das in den Proben enthaltene Lokalmaterial (Gesteine des Juragebirges und mittelländische Molasse) nicht berücksichtigt (für die erdgeschichtliche Interpretation aber sehr wohl), weil deren Beimengung bzw. Gehalt von Schotterlage zu Schotterlage meist stark schwankt und so keine wesentliche Aussage bezüglich der Geröllfazies zulässt. Ebenfalls nicht berücksichtigt wurde der Gehalt an Marmoren und niedriggradig metamorphen klastischen Gesteinen (welche vor allem aus den Bündnerschiefern stammen), weil deren Gehalt stark von der Transportdistanz im fliessenden Wasser abhängig ist. So enthalten glaziale oder randglaziale Ablagerungen bis zu 20\% dieser Gesteine (z.B. STB39), während sie glazifluvialen Schottern in der Regel fehlen.

Gemäß den Untersuchungen von GASSER \& Nabholz (1969) und GraF (in Bearbeitung) spielt bei der Zusammensetzung des Schwermineralspektums der eiszeitlichen Ablagerungen der Molasseuntergrund im Einzugsgebiet eine entscheidende Rolle. Zwar kann stets ein gewisser Anteil an direkt aus den Alpen stammenden Schwermineralien festgestellt werden (v.a. grüne Hornblenden), der größte Teil der
Schwermineralien stammt jedoch aus den Molasseablagerungen, insbesondere den Sandsteinen der näheren Umgebung einer bestimmten Probenahmestelle.

Im Untersuchungsgebiet ist vor allem die Obere Süsswassermolasse verbreitet. Im Bereich von Schaffhausen tritt die Untere Süsswassermolasse (USM) auf und in einem relativ schmalen Streifen auf dem Cholfirst die Obere Meeresmolasse (OMM). Die OSM kann in drei Fazien eingeteilt werden: im zentralen Bereich die Glimmersande, im S die Ausläufer des Hörnli-Schuttfächers und im NW die Jüngere Juranagelfluh. Die Ablagerungen des HörnliSchuttfächers spielen vor allem auf dem Seerücken eine große Rolle und erstrecken sich als einzelne Lagen bis zum Schiener Berg. Die Jüngere Juranagelfluh kommt lediglich im Bereich Thayngen-Eberfingen vor. Diese OSMFazien unterscheiden sich markant im Schwermineralspektrum. Die Glimmersande weisen stets einen auffällig hohen Gehalt an Granat auf (meist über $60 \%$ ), wogegen die Ablagerungen des Hörnli-Schuttfächers von Epidot dominiert werden. Die Juranagelfluh zeichnet sich durch einen relativ hohen Gehalt an Ultrastabilen (Zirkon, Rutil, Turmalin) aus.

\section{Feldbefunde}

In diesem Kapitel werden die einzelnen untersuchten Deckenschottervorkommen anhand von eigenen Befunde und Literaturangaben beschrieben. Die erwähnten Örtlichkeiten können Abbildung 3 entnommen, bzw. anhand der im Anhang angegebenen Koordinaten der Entnahmestellen petrographischer Proben lokalisiert werden, sofern diese nicht direkt im Text angegeben sind. Die Lageangaben beziehen sich auf das schweizerische Koordinatensystem. Für Lokalitäten in Deutschland werden zusätzlich die R/H-Werte angegeben. Die Lokalitätsbezeichnungen entsprechen weitgehend denen der Landeskarte der Schweiz 1:25.000. Im Text sind die untersuchten Geröllzählungen in Normalschrift (STM10), die Schwermineralzählungen in Kursivschrift angegeben (STM11). Die Grunddaten und Resultate der Zählungen 


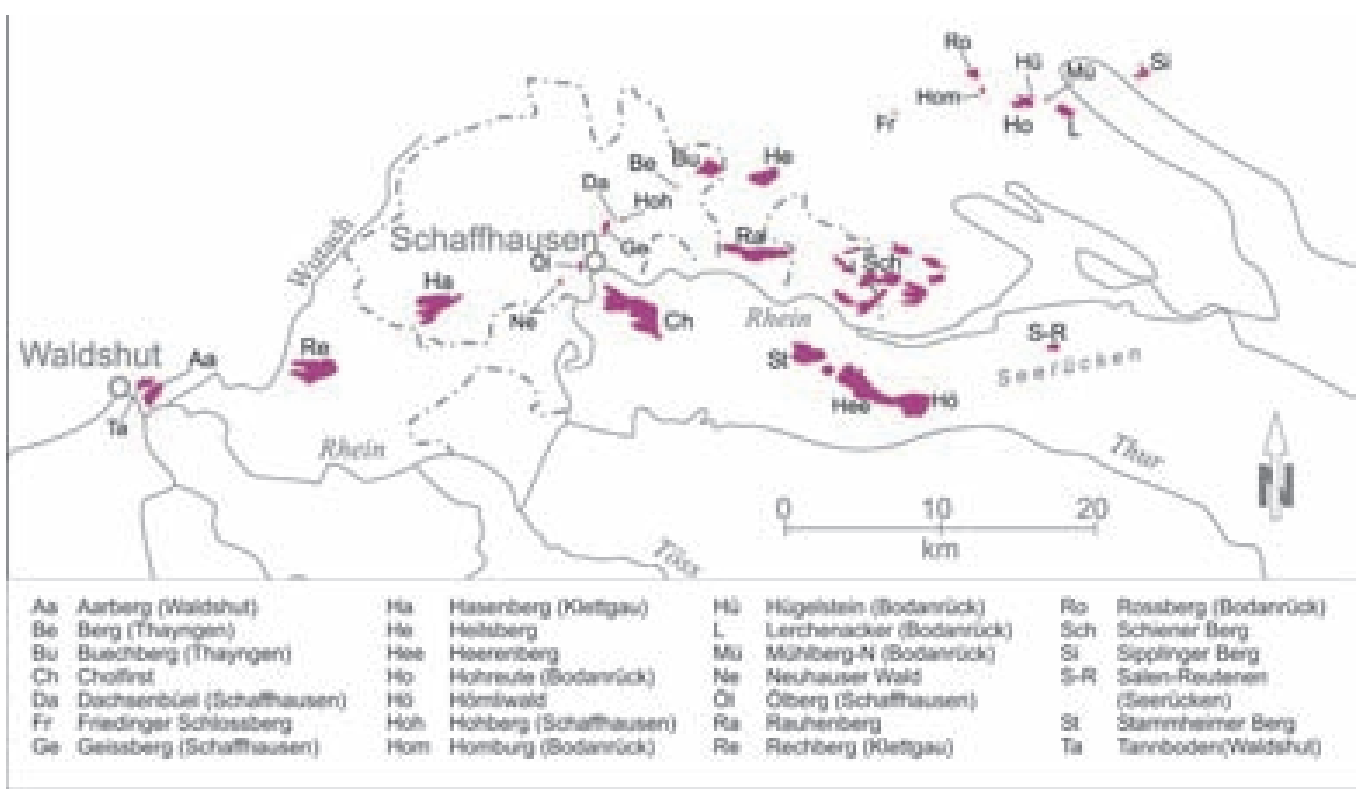

Abb. 3: Die für die vorliegende Arbeit untersuchten Vorkommen von Deckenschottern.

Fig. 3: Occurences of Deckenschotter in the study area.

sind in Anhang 1 (Gerölle) und in Anhang 2 (Schwermineralien) enthalten.

\subsection{Deckenschotter vom Hegau bis Schaffhausen}

Sipplinger Berg (Verwendete Literatur: SCHILl (1859), ERB (1934), ERB et al. (1961))

Im Gebiet des Sipplinger Bergs existieren zwei (heute) getrennte Vorkommen von Deckenschottern. Die Geländekante oberhalb des Haldenhofes wird durch verkittete Schotter gebildet, welche in exemplarischer Weise an einen ehemaligen Talhang angelagert sind (tiefste Vorkommen auf ca. $650 \mathrm{~m}$ ü.M. 724.150/296.300; R/H: 35'07'350/52'96'425). Heute ist unterhalb des Aussichtspunktes der ca. $30^{\circ}$ gegen $\mathrm{W}$ geneigte Kontakt zwischen Schotter und Molasse aufgeschlossen (He24, He24). Die Schotter weisen in den tiefsten Abschnitten gekrizte Geschiebe und zerdrückte Gerölle auf. Auf der Hochfläche beim Hochbehälter der Bodenseewasserversorgung kommen vor allem glazigene Ablagerungen vor (einst aufgeschlossen in der Baugrube des Hochbehälters und in Bohrungen, Auflagerungshöhe ca. 670-685 m ü.M.), welche lokal mit glazifluvialen Schottern vergesellschaftet sind ( $\mathrm{He} 23$, He23). Die Differenz der Auflagerungshöhe der beiden Sedimentpakete beträgt also mindestens $20 \mathrm{~m}$.

Bodanrück (Verwendete Literatur: ERB (1934), Schreiner $(1973,1991)$, Penck 1896, Penck \& BRÜCKNer 1901-1909)

Die Basis der Deckenschotter rechts des Dettelbaches (Vogelherd-Lerchenacker) liegt in $660 \mathrm{~m}$ Höhe, die Mächtigkeit beträgt rund $20 \mathrm{~m}$ (He22). Es kommen gekritzte Geschiebe vor. Im Gebiet Hohreute („Mühlberg-Süd“, He27, He27). In den Schottern konnten westliche Paläoströmungsrichtungen festgestellt werden. Im Gebiet Mühlberg-Süd sind möglicherweise zwei verschieden alte Ablagerungen zu unterschieden. Eine ältere Deckenschottereinheit mit Basis um 650 m ü.M. wird im SW von jüngeren, gletschernah abgelagerten Sedimenten gekappt. 
Auf beiden Seiten des Dettelbaches kommen weiter im $\mathrm{N}$ zwei rund $50 \mathrm{~m}$ tiefer gelegene Deckenschotterrelikte vor. Am Hügelstein (He21) liegen sie auf rund $615 \mathrm{~m}$ der Molasse auf (mit gekritzten Geschieben), auf der anderen Seite („Mühlberg-Nord“, He25, He25) liegt der Schotter auf $600 \mathrm{~m}$ der Molasse auf.

Rossberg - Homburg (Verwendete Literatur: Erb et al. (1961), Schreiner (1991))

Die Basis der Schotter liegt auf der E-Seite auf 587 m ü.M. (He26, He26). Die Mächtigkeit des Vorkommens beträgt etwa $20 \mathrm{~m}$. Es enthält Lagen aus glazigenen Ablagerungen. Weiter südlich kommen drei Relikte verkitteter Schotter vor, die jeweils auf rund $600 \mathrm{~m}$ ü.M. der Molasse auflagern. Die Felsoberfläche steigt gegen Westen auf etwas über 605 m ü.M. an.

Friedinger Schlossberg (Verwendete Literatur: Frei (1912a), SCHREINER (1973))

Unterhalb des Schlösschens auf dem Friedinger Schlossberg sind oberhalb von $530 \mathrm{~m}$ ü.M. ca. $13 \mathrm{~m}$ mächtige, verkittete Schotter aufgeschlossen (He28, He28). Oben sind grobe Gerölle recht häufig, vor allem Molassegesteine. Es kommen ausserdem Juliergranit, Amphibolite, Gneise, Flyschsandsteine, alpiner Buntsandstein und Nummulitenkalk vor.

Heilsberg (Verwendete Literatur: FREI (1912a), SCHREINER (1983))

Die Schotter des Heilsbergs erreichen eine Mächtigkeit von gegen $50 \mathrm{~m}$. Im Riedernhölzle, auf der NE-Seite des Hügels, steigt die Molasse in ihrem Liegenden bis auf über $530 \mathrm{~m}$ ü.M. auf. In einer kleinen Kiesgrube auf der N-Seite $(700.375 / 289.900 ; \mathrm{R} / \mathrm{H}$ : 34'83'350/52'90'375) sind die Schotter bis hinunter auf $510 \mathrm{~m}$ ü.M. ersichtlich, ebenso in Aufschlüssen auf der SW-Seite (z.B. in einer alten Kiesgrube, ca. 699.200/289.175, R/H: 34'82125/52'89'725. Die Schotterbasis liegt auf der S-Seite (Ruine Heilsberg (He13) auf rund $500 \mathrm{~m}$ ü.M. Bei diesem Vorkommen könnte es sich aber auch um ein versacktes Gesteinspaket handeln.

Buchberg bei Thayngen (Verwendete Literatur: Frei (1912a), HoFmAnN (1959, 1967a), SCHREINER (1983))

Die Basis der Deckenschotter liegt im S (Heerenhof, Chapf, He6, Heб) bei ca. 515 m ü.M. und steigt nordwärts an. Bei der ehemaligen Lehmgrube auf der E-Seite dürfte sie auf 525 m ü.M. liegen (He8, He8). Die Schotter reichten bis auf ca. $545 \mathrm{~m}$ ü.M. hinauf (Mächtigkeit rund $30 \mathrm{~m}$ ). Sie enthalten Amphibolite, Hornblende- und Biotitgneise, Muskovitschiefer, Quarzporphyre, Melaphyre, Spilite, Serizitquarzit sowie Flysch- und Molassesandsteine. In der erwähnten Grube wurden an der Basis der Schotter grosse Basaltblöcke aus dem Hegau gefunden, ebenso bis zu $1 \mathrm{~m}$ durchmessende Kalksandsteinblöcke aus der Juranagelfluh. In der Sandfraktion ist eine auffällige Anreicherung an (vulkanischem) Magnetit zu verzeichnen.

Berg bei Thayngen (Verwendete Literatur: Schalch (1883), Gutzwiller (1883))

Der kleine Rest von verkitteten Schottern bei der Lokalität Berg südöstlich von Thayngen (He1) ist bis auf rund $515 \mathrm{~m}$ ü.M. hinunter aufgeschlossen. Enthalten sind Phonolith und $\mathrm{Ba}-$ salt aus dem Hegau.

\section{Rauhenberg (Verwendete Literatur: Schreiner (1973), Frei (1912a))}

Die Auflagerungsfläche der Schotter ist offenbar generell gegen W, evtl. SW leicht geneigt. Am E-Ende ihrer Verbreitung (RHB2, RHB2) reicht die Molasse bis auf $562 \mathrm{~m}$ ü.M. hinauf, während etwa $1 \mathrm{~km}$ weiter westlich Aufschlüsse bis hinunter auf $550 \mathrm{~m}$ ü.M. vorkommen (RHB4). Im S reichen die Schotter wahrscheinlich bis auf $540 \mathrm{~m}$ ü.M. hinunter (verlassene Kiesgrube, RHB6). Die Geländemorphologie lässt aber die Möglichkeit offen, dass es sich bei dieser Lokalität um eine versackte Gesteinspar- 
tie handelt. Die Einregelung der Gerölle deutet auf eine Paläoströmungsrichtung nach $\mathrm{W}$ bis SW. Im E des Gebietes (701.800/284.550; R/H: 34'84'550/52'85'150) wurden zerdrückte Gerölle festgestellt.

\subsection{Schiener Berg}

Der Schiener Berg kann als Typusgebiet für die Deckenschotter des gegen W entwässernden Teils des Bodensee-Rheingletschers bezeichnet werden. Spätestens seit FrEI (1912a) werden hier Höhere und Tiefere Deckenschotter unterschieden, wobei damals das Schottervorkommen direkt unterhalb der ehemaligen Schrotzburg noch zu den Höheren Deckenschottern gestellt wurde. SchreIner (1991) gliederte die Schotter in drei Einheiten (Höhere, Mittlere und Tiefere Deckenschotter), welche er in Anlehnung an die Verhältnisse im östlichen Bodensee-Rheingletschergebiet den Eiszeiten Günz, Haslach und Mindel zuordnete. Die für die vorliegende Untersuchung anhand von Literaturangaben, vorhandenen Kartierungen und eigenen Feldbefunden gewonnenen Daten zur Morphologie und Höhenlage der Felsoberfläche, Schüttungsrichtungen glazifluvialer Ablagerungen usw. sind in Abbildung 4 dargestellt. Auf Angaben zur Schotterbasis wird im Text deshalb weitgehend verzichtet.

\section{Schrotzburg - Bohlinger Schlucht}

(Verwendete Literatur: GutzwiLler (1894),

Penck \& BRÜCKNER (1901-1909), Frei (1912a), Неiм (1919), ZAugG (2002), SCHREINER $(1965,1973))$

Frühen wurden die ca. 15 m mächtigen Schotter der Ruine der ehemaligen Schrotzburg (Schrotzburg-Schotter, Bezeichnung nach ZAUGG 2002, SBT8; SBT8, SBT17) zu den Höheren Deckenschottern gestellt. Heute ist bekannt, dass unter diesen Schottern eine maximal ca. $50 \mathrm{~m}$ mächtige Abfolge von glazigenen Diamikten (Schrotzburg-Till, Bezeichnung nach ZAUGG 2002) und zuunterst ein bis zu $30 \mathrm{~m}$ mächtiger glazifluvialer Schotter (Bohlingen-Schotter, SBT2, SBT2, SBT21) vor- kommen. Deshalb wird diese Abfolge aktuell zu den Tieferen Deckenschottern gestellt (z.B. SCHREINER 1973).

Die Felsmorphologie weist eine klare Rinnenstruktur entlang dem N-Rand des Plateaus auf (Schrotzburg-Rinne), welche sich gegen W möglicherweise in zwei Arme aufspaltet. Der gegen SW abzweigende Arm wurde auf Grund von Seismikbohrungen festgestellt. Diese Rinne weist eine Füllung aus Diamikten von über $50 \mathrm{~m}$ Mächtigkeit auf. Auf der rechten Seite davon scheint eine Felsterrasse vorzukommen, auf welcher verkittete Schotter liegen (Mächtigkeit ca. $20 \mathrm{~m}$ ). Möglicherweise ist diese Felsdepression jünger ist als der östliche Teil der SchrotzburgRinne. Ein Zusammenhang der Diamikte in der abzweigenden Rinne mit dem Schrotzburg-Till in der Hauptrinne kann allerdings nicht a priori ausgeschlossen werden.

Im Hauptteil der Rinne, deren Basis auf etwa 585 m ü.M. liegt, wie auch in ihrem gegen NW verlaufenden Arm besteht die Lockergesteinsfüllung unten aus den Bohlingen-Schottern, die vom Schrotzburg-Till überlagert werden. Den Abschluss des Profils bilden die Schrotzburg-Schotter. Nördlich der Schrotzburg steigt die Molasse wieder bis etwa $630 \mathrm{~m}$ ü.M. an (709.525/284.775; R/H: 34'92'350/52'85'250, Grobsand und Hörnli-Nagelfluh).

Weiter nördlich kommt ein kleines Relikt von verkitteten glazifluvialen Schottern vor, welches jenseits des Randes der Schrotzburg-Rinne liegt $\quad(709.475 / 284.800 ; \quad \mathrm{R} / \mathrm{H}$ : 34 '92'350/52'85'300). Es ist an einen steilen ehemaligen Hang angelagert (zwischen ca. 605-615 m ü.M.). Seiner Lage außerhalb der Schotzburg-Rinne deutet darauf hin, dass diese Schotter in einer separaten, vermutlich jüngeren Felsdepression entstanden sind als die Ablagerungen innerhalb der Schrotzburg-Rinne.

Die Bohlingen-Schotter sind als typische glazifluviale Schotter zu deuten. Sie weisen eine gegen oben graduell zunehmende Korngrößen auf. Das tiefstgelegene, sicher in situ befindliche Vorkommen von Bohlingen-Schottern kommt in der Bohlinger Schlucht auf einer Höhe von ca. 585 m ü.M. vor. Der Schrotzburg-Till ist nur schlecht aufgeschlossen. Wo 


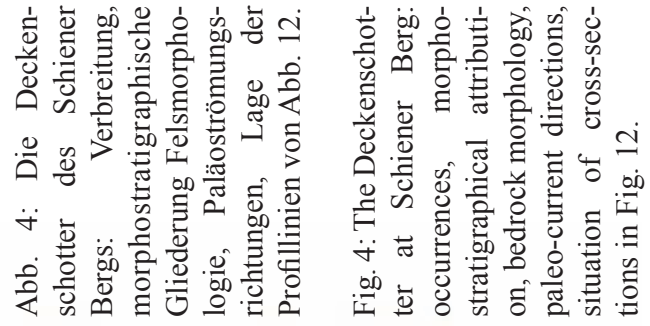

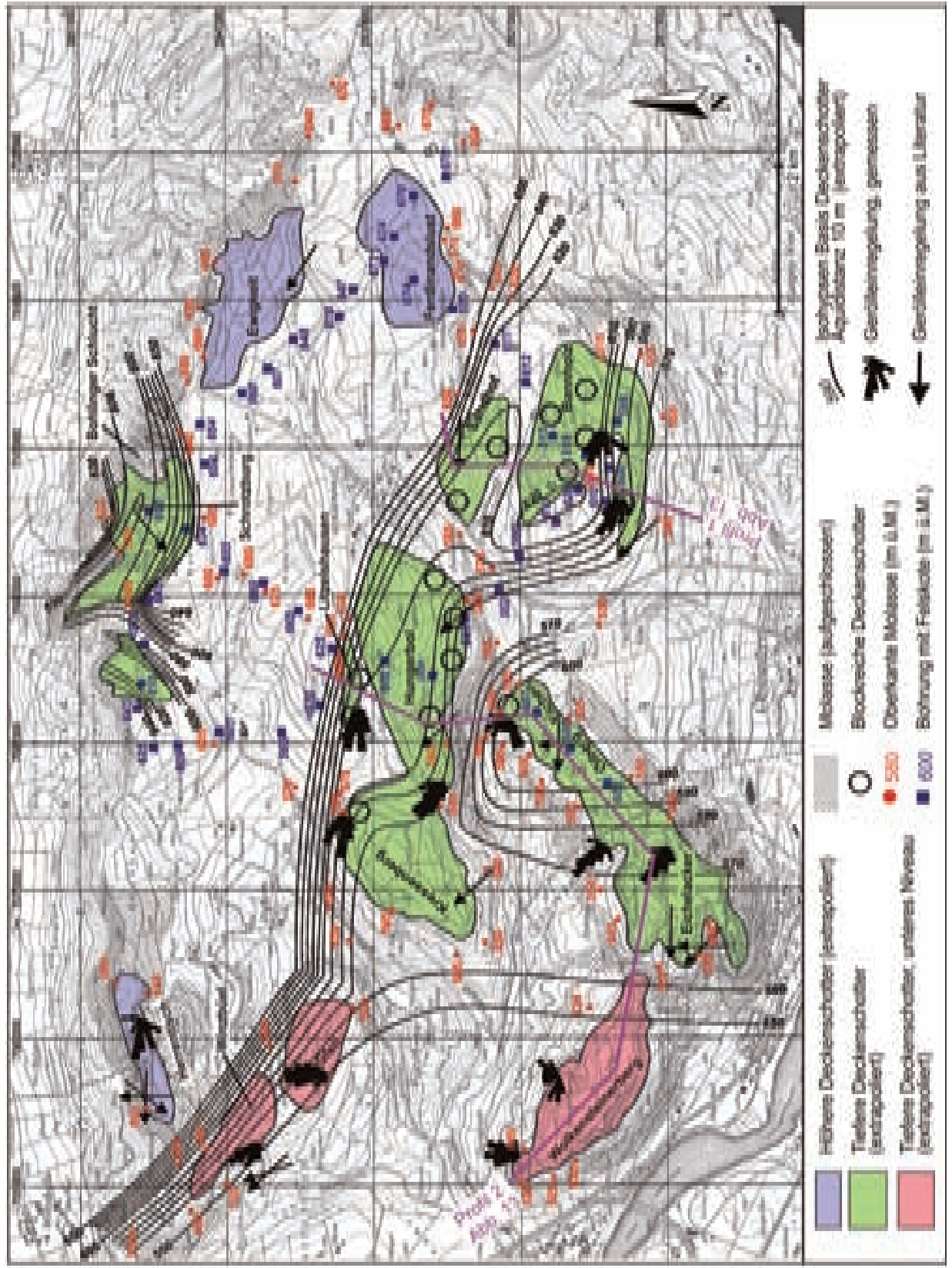




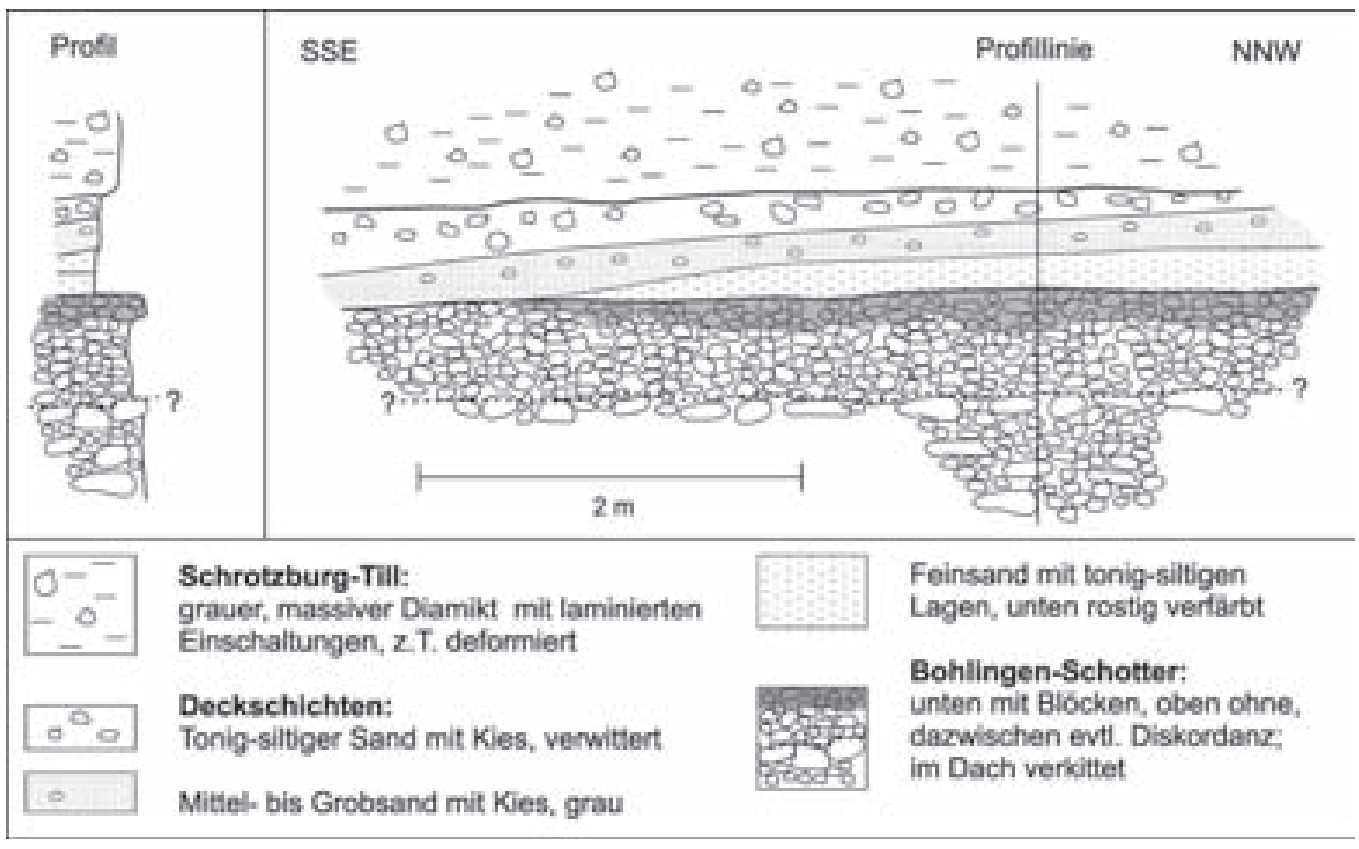

Abb. 5: Skizze des Schurfes in der Bohlinger Schlucht ca. 2 km nördlich von Schienen (709.200/284.650; R/H: 34'92'050/52'85'025).

Fig. 5: Outcrop at Bohlinger Schlucht, some $2 \mathrm{~km}$ north of the village of Schienen.

beobachtbar, handelt es sich um graue, matrixgestützte Diamikte; es kommen aber auch fein geschichtete beige Sedimente vor. Diese Indizien sowie die große Mächtigkeit der Einheit lassen darauf schließen, dass hier glaziale Beckensedimente vorliegen. Bei den Schrotzburg-Schottern handelt es sich um sandige Kiese mit schlecht gerundeten Komponenten und zahlreichen gekritzten Geschieben. Sie sind deshalb als gletschernah abgelagerte Sedimente zu deuten. Das Material wurde nach SW geschüttet. Die Schotter enthalten unter anderem Julier-Granit.

In einem Anriss in der Bohlinger Schlucht (709.200/285.650; R/H: 34'92'050/ 52'85'025) war im Winter 2001/2002 der Kontakt der Bohlingen-Schotter zum Schrotzburg-Till aufgeschlossen (Abb. 5).

Die Bohlingen-Schotter sind relativ grobkörnig ausgebildet (SBT37). Im Schurf sind die obersten ca. $70 \mathrm{~cm}$ (SBT38) demgegenüber merklich feinkörniger. Über den Schottern folgt eine ge- gen $0,8 \mathrm{~m}$ mächtige Deckschichtenserie. Sie besteht im rechten Teil des Schurfes aus einer Abfolge von tonig-siltigen und feinsandigen Ablagerungen, welche zum Teil eine Feinschichtung (mm-Bereich) aufweisen. Lokal können darin Lagerungsstörungen (Convolute bedding) festgestellt werden. Diese Sedimente sind unten durch Fe- und Mn-Hydroxide intensiv rostbraun bzw. braunschwarz verfärbt. Sie keilen gegen $\mathrm{S}$ allmählich aus und werden von grauen, sandigen (z.T. grobsandig-kiesigen) Ablagerungen diskordant überdeckt. Darin ist eine flache Schrägschichtung erkennbar. Es folgt eine gegen $\mathrm{S}$ mächtiger werdende Lage $(30-50 \mathrm{~cm})$ aus tonig-siltigem, sandigem Kies. Sand- und Feinfraktion sind entkalkt, die Gerölle (darunter auch Kalke) weisen oft Tonhäutchen auf. Im unteren Teil kommen kleine weisse Kalkkonkretionen vor. Die Schotter weisen dort, wo sie von feinkörnigen Sedimenten überlagert werden, zuoberst eine kalzitische Verkittung, eine intensive Imprägnation durch 
Fe- und Mn-Hydroxide sowie zahlreiche kleine Kalkkonkretionen auf. Die grobkörnigen Schotter sind bis in eine Tiefe von rund $1,5 \mathrm{~m}$ intensiv rostig verfärbt.

Die überlagernde Gesteinseinheit (SchrotzburgTill) besteht im Wesentlichen aus einem grauen matrixgestützten, relativ kiesarmen Diamikt (SBT39). In einzelnen tonig-siltigen bis feinsandigen Abschnitten lässt sich eine feine Laminierung feststellen. Daneben kommen dünne, oft steil stehende Feinsandlagen vor (Streichen ca. SE-NW). Gekritzte Geschiebe sind zahlreich. Lokal kann die Aufarbeitung der liegenden Ablagerungen festgestellt werden (z.B. anhand des Vorkommens von aus dem liegenden Schotter stammenden kleinen Kalkkonkretionen). Über die Lagerungsdichte des Sedimentes kann keine zuverlässige Aussage gemacht werden, weil es im Aufschluss durch Hangbewegungen, Verwitterung und Vegetation (Wurzeln) aufgelockert war. Einzelne kompakte diamiktische Schollen lassen jedoch eine recht große Lagerungsdichte erahnen, so dass eine Überfahrung durch Gletschereis durchaus möglich ist. Diese könnte gleichzeitig für eine gewisse glazialtektonische Überprägung des Materials verantwortlich sein (steil stehende Sandschichten).

Deckschichtenfolgen, wie sie die BohlingenSchotter tragen, sind im Dach von glazifluvialen Schottern häufig zu beobachten. Dies kann einerseits als graduelles Nachlassen der Transportenergie des Flusssystems gedeutet werden. Anderseits entstehen im Zuge eines Eisrückzuges oft erosive Terrassenflächen, die anschliessend nochmals eine Akkumulation erfahren (meist wenige Meter mächtig). Dabei werden die Schotter der vorangegangenen Akkumulation durch eine neue Schotterlage überdeckt (oft erkennbar anhand von Blocklagen oder anhand eines deutlichen Körnungsunterschiedes). Solche jüngere Akkumulationsflächen (,Rückzugsterrassen") können von späten Überschwemmungsereignissen nochmals erfasst werden, was zur Entstehung von sandigen und tonig-siltigen Deckschichten führt. Der deutliche Kontrast in der Körnung zwischen der kiesigen Deckschicht und den unterlagernden Schottern im Aufschluss Bohlinger Schlucht deutet auf eine solche Rückzugsterrassensituation hin. Die über den fluviatilen Sedimenten folgende Schicht aus vorverwittertem Material ist vermutlich als umgelagerter Hangschutt zu interpretieren. Das Auftreten von Tonhäutchen deutet darauf hin, dass nach der Ablagerung noch eine gewisse pedogenetische Überprägung stattgefunden hat. $\mathrm{Ob}$ die oben erwähnten auffälligen Fe- und Mn-Hydroxidimprägnationen sowie die Kalkfällungen (Verkittung und Konkretionen) ebenfalls als pedogenetische Phänomene der gleichen Phase zu deuten sind, kann anhand des Aufschlusses nicht definitiv entschieden werden. Immerhin deutet das Vorkommen von aufgearbeiteten Kalkkonkretionen im Schrotzburg-Till darauf hin, dass diese vor den Diamikten entstanden sind.

In der Bohlinger Schlucht weisen die Bohlingen-Schotter demnach oben eine typische fluviatile Rückzugssequenz auf und eine Lage aus Hangschutt auf, die Anzeichen einer gewissen pedogenen Überprägung zeigen. Dies lässt auf einen zeitlichen Hiatus zwischen BohlingenSchotter und Schrotzburg-Till schließen. Eine genetisch kontinuierliche, durch einen Gletschervorstoss verursachte Sedimentabfolge dürfte jedenfalls ausser Betracht fallen.

\section{Ferdinandslust, Ewigkeit, Herrentisch}

(Verwendete Literatur: SCHREINER (1965, 1973,

$$
\text { 1991, 1992a), Frei (1912a)) }
$$

Aus Gründen der Übersichtlichkeit wurde darauf verzichtet, in Abbildung 4 die Felsoberfläche im Liegenden der Höheren Deckenschotter anzugeben. Die vorhandenen Daten lassen generell auf ein sanftes Absinken der Felsoberfläche von SE nach NW schließen. Während östlich von Ferdinandslust Molasseaufschlüsse bis gegen $680 \mathrm{~m}$ ü.M. vorhanden sind, lagern die Deckenschotter im Gebiet Herrentisch auf rund $665 \mathrm{~m}$ ü.M. dem Fels auf.

Die Deckenschotter NE von Ferdinandslust sind heute nur entlang dem S-Hang in zwei kleinen Aufschlüssen ersichtlich (SBH4). In einer kleinen Grube auf der Hochfläche (711.500/282.550; R/H: 34'94'450/52'82'725) sind unverkittete, schlecht sortierte Schotter 
vorhanden, mit praktisch frischen Dolomitgeröllen. Dabei dürfte es sich um deutlich jüngere kaltzeitliche Sedimente handeln.

Im Gebiet Herrentisch sind die Schotter in einer Kiesgrube auf der SE-Seite des Vorkommens (SBH1, SBH1) sowie in mehreren natürlichen Aufschlüssen im NW ersichtlich. In einer Kiesgrube $(711.075 / 283.650 ; \mathrm{R} / \mathrm{H}$ : 34'94'000/52'83'950) wurde eine Strömungsrichtung nach NW ermittelt.

Ein ehemalige kleine Abbaustelle am S-Hang des Herrentischs (705.950/284.550; R/H: 34'88'900/52'85'000) ist heute völlig verstürzt und überwachsen. An einer Wegbiegung östlich davon (SBH3, SBH3) ist der Schotter aufgeschlossen. Am N-Hang kann er über eine grössere Strecke beobachtet werden, wo er eine ca. $10 \mathrm{~m}$ mächtige Schicht auf der Molasse bildet (SBH2). Die Gerölle sind dominant nach W eingeregelt.

\section{Bannholz-Sandhof}

(Verwendete Literatur: SCHREINER (1965, 1991, 1992a), Zaugg (2002), Frei (1912a))

Nach SchreIner (1991, 1992a) können im Gebiet Bannholz anhand der Auflagerungshöhen zwei verschieden alte Schotter unterschieden werden („Bannholz-N“ und „Bannholz-S“). Sie sollen durch eine Zone mit Molassegesteinen von einander abgetrennt sein. Im fraglichen Übergangsbereich waren jedoch Anfangs 2002 in etlichen Wurzeltellern verkittete Schotter ersichtlich, die dort offenbar in sehr geringer Tiefe (ohne nennenswerte Bedeckung durch jüngere Ablagerungen) anstehen.

Die Schotter von Bannholz-N sind in den höheren Lagen ausgesprochen reich an groben Geröllen und Blöcken (z.T. über $70 \mathrm{~cm}$ Durchmesser) sowie an zerdrückten Geröllen. Dies ist in mehreren verlassenen Gruben ersichtlich $(710.400 / 281.500 ; \quad \mathrm{R} / \mathrm{H}$ : 34'93'275/52'81'850, oder 709.900/281.600; R/H: 34'92'775/52'81'950, SBT15, oder 710.250/281.800; R/H: 34'93'075/52'82'125). Auch im angesprochenen Übergangsbereich zwischen den beiden ScHREINERschen Schottereinheiten sind solch grobe Gerölle verbreitet.
Im südlichen Bereich des Bannholzes sind die Deckenschotter in einer Kiesgrube aufgeschlossen (SBT9, SBT9). Darin kommen Julier und Albula-Granite vor (Paläoströmung nach NW). Die hier heute aufgeschlossenen Schotter bestehen fast ausschließlich aus schräg geschichteten Einheiten. In der Nachbarschaft dieser Kiesgrube liegen mehrere Quellfassungen, die auf einen stauenden Horizont (vermutlich Molasse) auf rund 570 m ü.M. (oder wenig darunter) schließen lassen. Die Schotter reichen bis in eine Höhe von knapp 620 m ü.M. In dieser Höhe befindet sich eine verlassene Kiesgrube (Paläoströmung nach NW). Im obersten Abschnitt (oberhalb von ca. $615 \mathrm{~m}$ ü.M.) werden die Schotter auffällig grobkörnig bis blockig.

In einer ca. $400 \mathrm{~m}$ westlich vom Unterbühlhof gelegenen, weitgehend verfallenen Kiesgrube (710.475/281.250; R/H: 34'93'300/52'81'575) sind diamiktische Schotter mit gekritzten Geschieben und glazigenen Einschaltungen vorhanden.

Durch einen flachen Taleinschnitt vom Bannholz getrennt, kommen auf dem Hügel westlich vom Sandhof (südlich von Schienen) ebenfalls Deckenschotter vor. In einer verlassenen Kiesgrube im S dieses Hügels (SBT18) ist eine wechselhafte Lockergesteinsabfolge aufgeschlossen, die neben verkitteten Schottern in ausgeprägter Blockfazies auch rein sandige Schichten umfasst. Auf dem höchsten Punkt des Hügels befindet sich eine kleine Kiesgrube (709.950/282.425; R/H: 34'92'850/52'82'775), welche gletschernah abgelagerte, z.T. verkittete Schotter mit einzelnen diamiktischen Lagen aufschließt. Eine ca. 2 m mächtige Lage verkitteter, gut abgerollter Schotter schliesst das Profil ab. Ein weiterer Aufschluss mit blockigem Schotter befindet sich im Böschungsanschnitt der Strasse Öhningen-Schienen.

\section{Litzelshausen - Hungerbol (Verwendete Literatur: SCHREINER (1965), FrEI (1912a))}

Die Deckenschotter nordöstlich von Litzelshausen lagern an einen alten Hang an. Dessen Verlauf kann anhand von Molasseaufschlüssen 


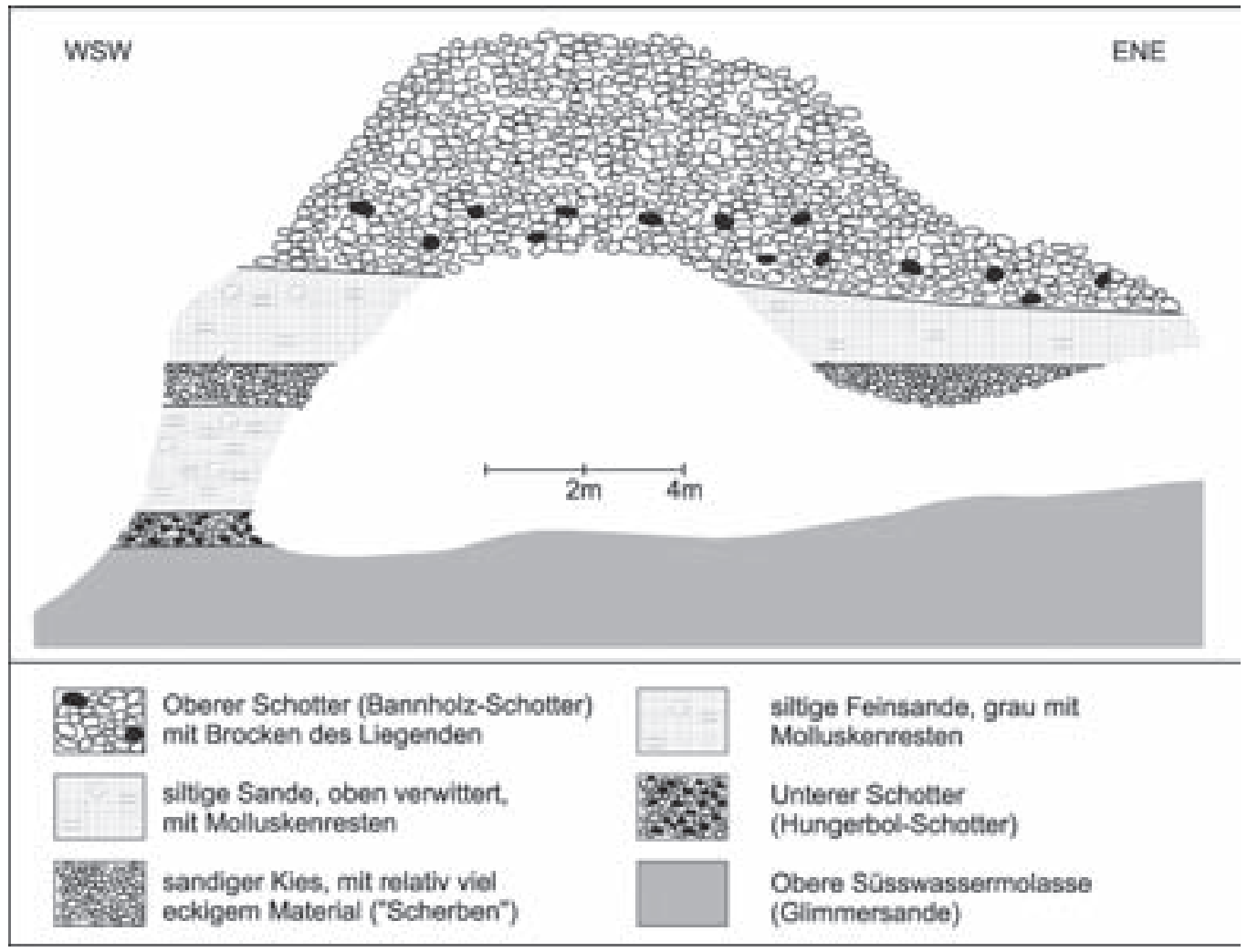

Abb. 6: Skizze der im basalen Bereich der Deckenschotter vom Hungerbol westlich von Schienen aufgeschlossenen fluviatile Sedimente (708.100/282.500; R/H: 34'90'750/52'82'900).

Fig. 6: Outcrop of fluviatile sediments at the base of the Deckenschotter at Hungerbol, west of the village of Schienen.

recht genau angegeben werden (vgl. Abb. 4). Die Schotter sind heute vor allem entlang der Strasse Schienen-Litzelshausen aufgeschlossen (SBT27, SBT27). Es handelt sich dabei um eine eigentliche Blockfazies. Zerdrückte Gerölle sind vorhanden.

Im Gebiet Hungerbol enthalten die Schotter im $\mathrm{E}$, also in den höheren Abschnitten des Profils, zahlreiche Blöcke von bis über $50 \mathrm{~cm}$ Durchmesser (Blockfazies, SBT35). Zerdrückte Gerölle sind nicht selten. Gegen W nimmt der Anteil an Blöcken allmählich ab, die Schotter bleiben aber sehr grobkörnig (Paläoströmung nach $\mathrm{W}$ bis NW).

Im unteren Abschnitt der Schotter des Hungerbol ist auf rund $585 \mathrm{~m}$ ü.M. (Kontakt $\mathrm{zu}$ Glimmersanden der Molasse aufgeschlossen) eine Abfolge von sandigen bis kiesigen Ablagerungen eingelagert (708.100/282.500; R/H: 34'90'750/52'82'900, Abb. 6). Die Abfolge beginnt mit einer ca. $80 \mathrm{~cm}$ mächtigen Schotterlage (SBT32, SBT40), welche gegen W (bei sinkender Schotterbasis) bis auf mindestens $4 \mathrm{~m}$ anwächst. Darüber folgen rund 2,4 m mächtige siltige Sande von grauer Farbe. In den obersten 80 $\mathrm{cm}$ sind die Sande fast siltfrei und locker, während im unteren Abschnitt das Material kompakt und recht hart ist. Eine horizontale Schichtung ist nur im oberen Abschnitt zu erkennen. Die Sedimente enthalten Schneckenschalen. Darüber folgt eine ca. $70 \mathrm{~cm}$ mächtige Schotterlage, die relativ viel aufgearbeitetes Geröllmaterial («Verwitterungsscherben») enthält. Ihr oberster Abschnitt (ca. 5-10 cm) ist stark verkittet und 
weist $\mathrm{Fe}$ - und Mn-Hydroxid-imprägnationen auf. Über den Schottern folgen maximal 1,8 $\mathrm{m}$ mächtige siltige Sande, die im obersten Abschnitt ein Lage aus siltigem Ton tragen. Lokal ist eine horizontale Schichtung erkennbar. Es sind wiederum Schneckenschalen enthalten. Die Sande sind durch Fe- und Mn-Hydroxide lagig rostig oder dunkelbraun verfärbt (manchmal eine schräge Schichtung vortäuschend). Die obersten rund 30-50 cm sind entkalkt. Die gesamte Abfolge wird durch relativ grobkörnige Schotter überlagert, welche in den untersten $2 \mathrm{~m}$ aufgearbeitetes Material der liegenden feinkörnigen Serie enthalten (SBT26, SBT26).

Die Deckenschotter vom Hungerbol enthalten offenbar eine recht mächtige Abfolge von fluviatilen Sedimenten. Die Ablagerungsdynamik war zur Zeit ihrer Ablagerung stark von der üblichen eiszeitlichen Dynamik verschieden. Sie entstanden während einer Phase mit stark reduzierter Wasserführung in der Hungerbol-Rinne. Die Entkalkung ihres obersten Abschnittes sowie die in den hangenden Schottern fehlenden Eisenund Manganhydroxidimprägnationen lassen an eine pedogentische Überprägung denken, ebenso die konkretionären Kalkausscheidung in den Schotterlagen. Möglicherweise dokumentieren diese Ablagerungen eine temperierte Phase während der Deckenschotterbildung.

\section{Kressenberg, Eichelacker-Ölberg-Eichen}

(Verwendete Literatur: Hofmann \& HantKe (1964), Frei (1912a), Geiger (1943), SCHREINER (1965))

Die Auflagerungsfläche der Deckenschotter des Kressenbergs steigt von $\mathrm{S}$ gegen $\mathrm{N}$ (SBT31, SBT31, SBT34) an. Dort enthalten sie Lagen mit Geröllen von z.T. über $50 \mathrm{~cm}$ Durchmesser (z.B. beim Eingang der Grube bei 707.575/283.050; R/H: 34'90'475/52'83'400, Paläoströmung nach $\mathrm{W}$ ).

Die Auflagerungsfläche der Schotter des Plateaus von Eichelacker-Ölberg-Eichen steigt generell von SW nach NE an. Einregelungsmessungen ergaben Schüttungsrichtungen nach W bis NW. Ein kleiner Aufschluss auf der W-Seite zeigt Schotter mit nordwestlicher
Schüttungsrichtung (SBT36). Ganz im N enthalten die Schotter in ihrem unteren Abschnitt mehrere Lagen mit auffällig grossen Geröllen (SBT33, Durchmesser z.T. über $50 \mathrm{~cm}$, alpines Material und Molassesandsteinknauer). Die Schotter wurden dort gegen $\mathrm{W}$ geschüttet.

\section{Wolkensteiner Berg, Gfell, Winzbüel}

(Verwendete Literatur: HüBSCHER (1961), Frei (1912a), Schreiner (1991))

Am Wolkensteiner Berg ist es wegen mächtiger Block- und Hangschuttmassen sehr schwierig, Geometrie und Höhenlage der Auflagerungsfläche der Deckenschotter zu rekonstruieren. Außer in einer verlassenen Kiesgrube (SBT22) liegen heute am S-Hang keine Aufschlüsse unterhalb von $580 \mathrm{~m}$ ü.M. vor. Im E (Zieglerhäuli) liegt findet sich Molasse bis auf rund 575 m ü.M. Der am tiefsten gelegene Deckenschotteraufschluss (eine kleine, verlassen Kiesgrube) befindet sich Am N-Hang sind in einer verlassenen Kiesgrube (SBT6, SBT6) Schotter bis auf rund $550 \mathrm{~m}$ ü.M. hinunter ersichtlich. Die Basis der Schotter dürfte noch etwas tiefer liegen (vielleicht rund 540 m ü.M.). Die Paläoströmung war nach $\mathrm{N}$ bis NW gerichtet.

Die Deckenschotter im Gebiet von Gfell und Winzbüel SE von Ramsen erstrecken sich etwa bis zur Lokalität Widem. Weiter im N (beim Eichholz) kommen zwar immer wieder verkittete Schotter vor, diese sind aber als verschleppte Blöcke innerhalb einer jüngeren glazigenen Ablagerung zu deuten. In der Kiesgrube im Gfell (SBT25) wie am Winzbüel (SBT24, SBT24) kommen einzelne feinanteilreichere Lagen vor. Die Paläoströmung war gegen $\mathrm{N}$ bis NW gerichtet.

\subsection{Seerücken bis Stammerberg}

Gebiet von Salen-Reutenen (Verwendete Literatur: FRÜH (1910), ZAUGG (2001), HantKe (1962), Büchi + Müller AG (1982), ERB (1934), Frei (1912b), PENCK \& BRÜCKNER (1901-1909), Geiger (1943))

Die Schotter von Salen-Reutenen sind südlich 
der Straße Salen-Reutenen auf einer Fläche von rund $2 \times 1 \mathrm{~km}$ verbreitet und erstrecken sich nördlich davon bis zur Geländekante, welche die Hochfläche von Reutenen gegen $\mathrm{N}$ begrenzt. Die Auflagerungshöhe der Schotter beträgt im Allgemeinen ca. 695-705 m ü.M., sinkt aber ganz im S unter $685 \mathrm{~m}$ ü.M. Auch weiter westlich, im Gebiet Heidenwald kommen verkittete Schotter vor, die in einer Höhe von ca. 660 m ü.M. der Molasse auflagern. $\mathrm{Ob}$ diese mit den östlichen Vorkommen zu verbinden sind, ist anhand der Aufschlussverhältnisse unklar.

In der alten Kiesgrube südlich von Reutenen (STM3, STM3, STM4) weisen die Schotter eine ausgeprägte Schrägschichtung auf (Mächtigkeit über $6 \mathrm{~m}$ ). Unter den Gesteinen kommen aplitische Gneise, Amphibolite, Glimmerschiefer, Quarzdiorit und Julier-Granit vor. Das Schüttungszentrum dürfte recht nahe gelegen haben, sind die Komponenten doch schlecht gerundet und es kommen gekritzte Geschiebe vor. Ein kleiner Aufschluss am Schnäggbüel (STM13) zeigte ebenfalls Schrägschichtung, wobei die Aufschlussverhältnisse aber keine Aussage darüber zulassen, ob es sich bei dieser Schichtung lediglich um ein kleinräumiges Phänomen oder insgesamt um eine deltaartige Ablagerung handelt. Anhand von diesen beiden Lokalitäten allein darf aber nicht davon ausgegangen werden, dass das gesamte Schottervorkommen von Salen-Reutenen eine Deltaablagerung darstellt. Im Gebiet Heidenwald ist keine Deltaschichtung in den Schottern festzustellen, sondern eine horizontal gelagerte Fazies mit grossen Blöcken (z.T. gekritzt). Insgesamt weisen die Schottern eine Schüttung nach $\mathrm{N}$ bis $\mathrm{W}$ auf.

\section{Stammerberg-Heerenberg-Hörnliwald}

(Verwendete Literatur: HofmanN (1967b), FrüH (1910), BüCHI + MüLler AG (1993, 1999), Haldimann \& Frey (1991), Penck (1896), Frei (1912a), Geiger (1943), Heim (1919), BЕСK (1933))

Die für die vorliegende Untersuchung anhand von Literaturangaben, vorhandenen Kartierungen und eigenen Feldbefunden gewonnenen
Daten zur Morphologie und Höhenlage der Felsoberfläche, die Schüttungsrichtungen glazifluvialer Ablagerungen usw. sind in Abbildung 7 dargestellt.

Die Deckenschotter des Hügelzuges zwischen Herdern im Kanton Thurgau und dem zürcherischen Stammheim sind nur an relativ wenigen Stellen aufgeschlossen, weshalb über den internen Aufbau der Ablagerungen nur punktuelle Angaben vorliegen. Ihre größte nachweisbare Mächtigkeit erreichen sie im NW, wo sie rund $45 \mathrm{~m}$ messen. Nur an wenigen Stellen ist eine Ermittlung der Paläoströmungsrichtung der Schmelzwässer möglich. Sie ergeben generell eine Schüttung nach WNW. Entsprechend der geringen Datendichte ist ihre Auflagerungsfläche auf den Molasseschichten schwierig zu rekonstruieren (vgl. Abb. 7). Die vorhandenen Daten deuten auf eine Gliederung in zwei Rinnenstrukturen hin, die sich im Gebiet Stammerberg vereinigen. Die eine Rinnenstruktur dehnt sich über das Gebiet Hörnliwald und Heerenberg bis hin zum Stammerberg aus. Die Felsoberfläche liegt am N-Rand des Hügels allgemein tiefer als im S. Der südliche Rand dieser flachen Rinne ist oberhalb von Nussbaumen angedeutet. Auf dem Stammerberg scheint zusätzlich eine zweite, etwas engere Rinnenstruktur zu existieren, welche von SE her einmündet. Auf Grund der Aufschlussverhältnisse wäre ihre Fortsetzung wahrscheinlich im Gebiet Vorder Hütten (ca. 702.000/278.300) zu suchen (auf Abb. 7 so angegeben), wo mehrere Quellen auf rund $560 \mathrm{~m}$ ü.M. im Molassefels gefasst sind.

Im Gebiet zwischen Oberstammheim und Nussbaumen im S und Kaltenbach im N kommt eine markante Felsdepression vor (Abb. 7). Eine Seismikbohrung durchfuhr hier zunächst rund $26 \mathrm{~m}$ mächtige, überwiegend feinkörnige Diamikte. Entsprechende Ablagerungen sind im Tobel südlich des Huebhofs (705.000/277.500) aufgeschlossen. Darunter folgen bis in etwa $35 \mathrm{~m}$ Tiefe (344 m ü.M.) teilweise verkittete, wahrscheinlich glazifluviale Kiese (deren Verbreitung wurde in Abb. 7 bewusst schematisch kreisrund angegeben, weil bisher keine weiteren Belege für diese Schot- 


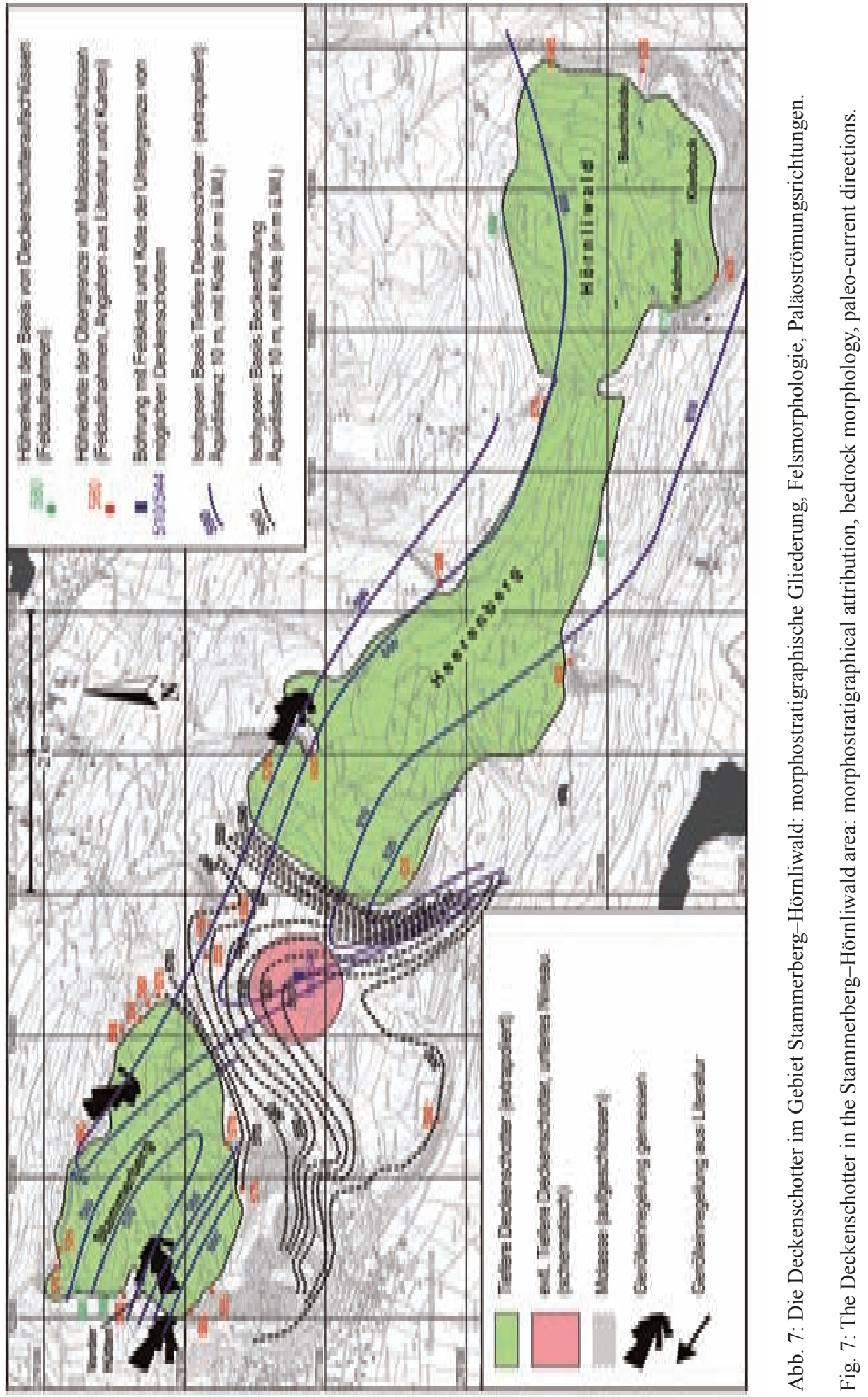


ter vorliegen). Diese Kiese werden von einer rund $34 \mathrm{~m}$ mächtigen Abfolge von eiszeitlichen Beckenablagerungen (evtl. mit glazigenen Einschaltungen) unterlagert. Die Molasse wurde auf 510 m ü.M. erreicht. Die auf Abbildung 7 dargestellte Felsmorphologie beruht auf der erwähnten Deutung der untersten Lockergesteinseinheit als glaziale Beckensedimente. Die Felsaufschlüsse lassen die Interpretation zu, dass sich dieses Becken von $\mathrm{S}$ her in den Hügel hinein erstrecken, diesen aber nicht vollständig durchstossen würde. Für ein von N einmündendes Becken scheint zu wenig Platz zu sein (was aber anhand der schmalen Datenbasis nicht als gesichert betrachtet werden darf). Die auf den Beckensedimenten auflagernden Schotter dürften daher, ausgehend von der oben skizzierten Interpretation der Felsdepression, gegen $\mathrm{N}$ oder NNE geschüttet worden sein, also in Richtung des westlichen Teils des Schiener Bergs.

Zum Alter dieses postulierten glazialen Beckens liegen bisher keine Angaben vor. Im angrenzenden Stammheimer Tal und auch im Thurtal sind ausgedehnte glaziale Becken bekannt, welche wahrscheinlich in den Komplex der Hoch- und Niederterrassen zu stellen und somit jünger als die Deckenschotter sind. Weil das Becken auf dem Stammerberg aus geomorphologischer Sicht (Höhenlage, Geometrie) nur schwer in den Kontext dieser Becken passt, wird vorläufig von einem höheren Alter ausgegangen und eine Zugehörigkeit zu den Deckenschottern angenommen.

In den Schottern des Stammerbergs (früher als Hohenegg bezeichnet) kommt eine Lage mit glazigenen Sedimenten vor (wahrscheinlich 702.550/278.875). An einer benachbarten Stelle wurde eine Lage mit gekritzten Geschieben festgestellt.

Für den Bereich des Hörnliwaldes konnte GEIGER (1943) eine Gliederung der Deckenschotter aufzeigen. Er unterschied zwei verschiedene Schüttungen. In der ehemaligen Kiesgrube am Boll nördlich von Kalchrain (709.300/274.300) war eine untere Schottereinheit aufgeschlossen, deren oberster Bereich stark zementiert war und zudem Gletscherschliffe aufwies. Darüber waren blockige Schotter aufgeschlossen. Er deu- tete diese Sedimentabfolge als Gletschervorstossfazies, wobei das Eis bis mindestens über Kalchrain hinaus vorgestossen wäre. Ein grösserer zeitlicher Hiatus kann seiner Meinung nach aber nicht ausgeschlossen werden. Die tieferen Anteile der Deckenschotter sind heute noch in einer ehemaligen Kiesgrube nördlich der Buechhalde (610 m ü.M., STM5) aufgeschlossen und entsprechen dem von GEIGER (1943) angegebenen Bild der unteren Schotter. Ebenso diejenigen der ehemaligen Kiesgrube am Heerenberg (708.575/275.100, $605 \mathrm{~m}$ ü.M.). Die oberen, blockigen Schotter waren auch in der ehemaligen Kiesgrube südwestlich des Berghofs aufgeschlossen („Kleebuck“, STM14). Es dürfte sich um gletschernah entstandene (feinanteilreiche, schlecht sortierte) Schotter handeln, welche Julier-Granit sowie vielleicht aus dem Adula-Gebiet stammenden Muskovitgneis enthalten.

Die Verhältnisse auf dem Stammerberg veranlassten BECK (1933) von zwei Gletschervorstössen, einem älteren Herdern-Vorstoß und einem jüngeren Stammheimer Vorstoß zu sprechen. Der ältere wäre demnach für die Entstehung der unteren Schotter verantwortlich, welche nach ihrer Verkittung beim späteren Stammheimer Vorstoß von Eis überfahren worden wären.

\subsection{Gegend um Schaffhausen, Klettgau}

Cholfirst (Verwendete Literatur: FREI (1912a), Büchi + Müller AG (2002), Hug (1907))

Die Auflagerungsfläche der Deckenschotter des Cholfirsts senkt sich allgemein von SE nach NW (Abb. 8). Im Bereich Hinterer Stich (ca. 693.000/280.200) steigt die Molasse bis auf rund $540 \mathrm{~m}$ ü.M. an. Dadurch ergibt sich für die Felsmorphologie das Bild einer flachen Rinne im SE des Cholfirsts (Basis etwas über $530 \mathrm{~m}$ ü.M). Die südliche Begrenzung dieser Rinne ist von der im Bereich des Vorderen Hörnli oberhalb von Benken markant ansteigenden Molasse markiert. Im Gebiet Hinterer Stich ist eine Hochzone vorhanden, die gegen $\mathrm{N}$ in eine zweite Rinne mit Basis unter 500 m ü.M. übergeht. Diese Gliederung der Auflagerungsfläche 


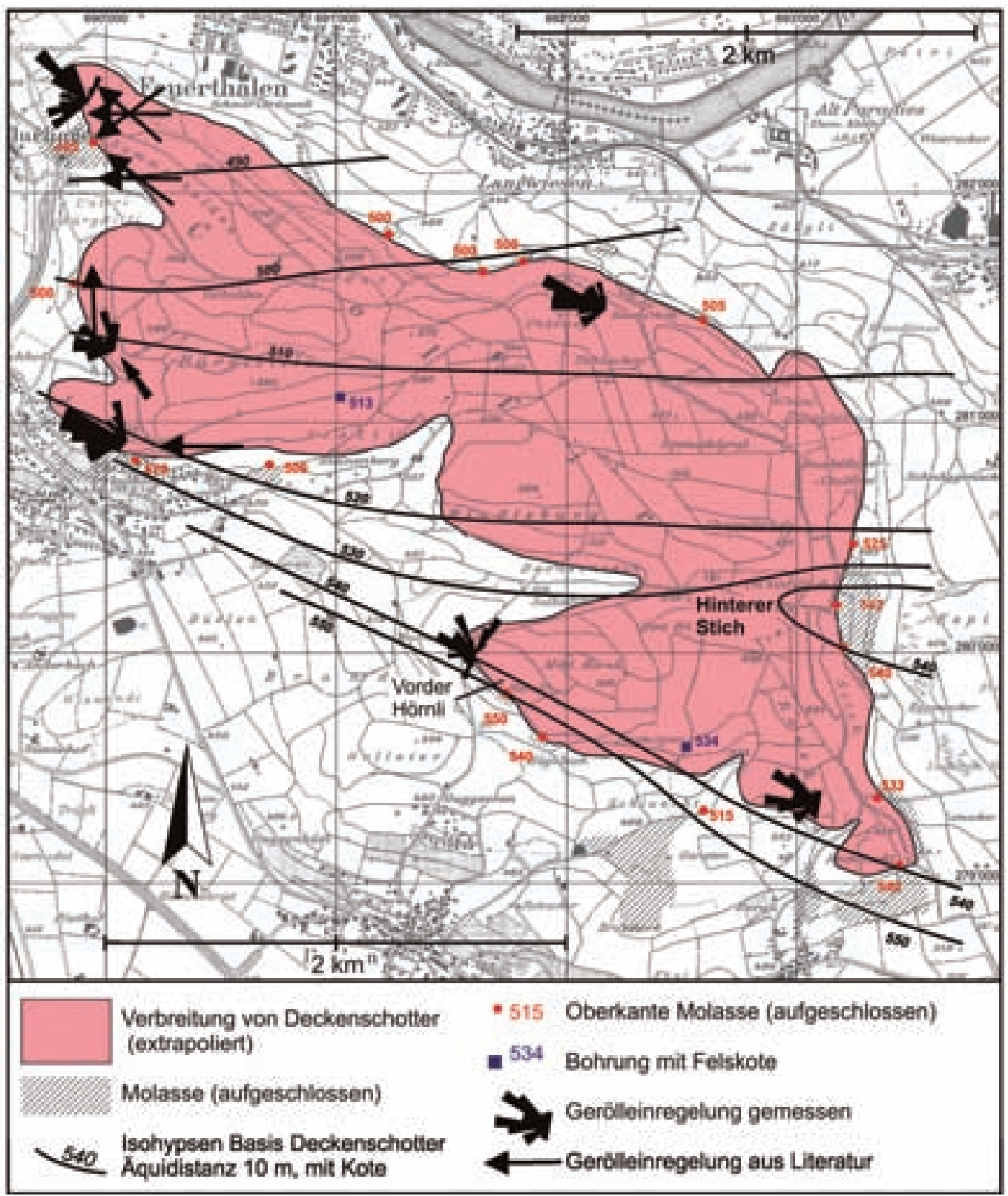

Abb. 8: Die Deckenschotter vom Cholfirst. Felsmorphologie, Paläoströmungsrichtungen.

Fig. 8: The Deckenschotter at Cholfirst: bedrock morphology, paleo-current directions. 
verschwindet gegen W. Die tiefste Lage der Schotterbasis liegt südwestlich von Feuerthalen bei rund $480 \mathrm{~m}$ ü.M. Bei den Schottern handelt es sich um glazifluviale Schotter, die weder auffällige Groblagen noch Einschaltungen von glazigenen Sedimenten oder Feinsedimenten aufweisen. Die Einregelung der Schotter lässt generell auf eine Paläoströmung des Schmelzwassers nach WNW bis NW schließen.

\section{Hohberg, Dachsenbühl, Geissberg; Ölberg-Galgenbuck, Neuhauserwald}

(Verwendete Literatur: FREI (1912a), HÜBSCHER (1961), Hofmann (1981), MBN AG (2004), Penck (1896), Verderber (1992))

Auf dem Hohberg sind die Deckenschotter vor allem auf der SE-Seite aufgeschlossen, z.B. in einer kleinen ehemaligen Abbaustelle (He12). Die maximal etwa $20 \mathrm{~m}$ mächtigen Schotter dürften auf rund $500 \mathrm{~m}$ ü.M. dem Fels auflagern. Die Einregelung der flachen Gerölle deutet auf wechselhafte Paläoströmungsverhältnisse mit einer Dominanz nach S.

Auf dem Dachsenbühl (ca. 690.650/286.450) sind keine Aufschlüsse vorhanden, einzig kleine Blöcke verkitteten Schotters deuten darauf hin, dass hier ein Deckenschottervorkommen existieren könnte.

Auf dem Geissberg weist die Auflagerungsfläche der Deckenschotter ein deutliches Gefälle nach SE auf, welches auf einen alten, etwa NNE-SSW verlaufenden Talhang aus Malmkalk hindeutet. Etwa in der Mitte des nordöstlichen Hanges (690.050/286.375) kann das Ansteigen des Kalkes auf kurzer Distanz beobachtet werden. Im SE des Hügels liegt die Basis der etwa $20 \mathrm{~m}$ mächtigen Schotter unter $500 \mathrm{~m}$ ü.M. Auf dem Hügel beim Kantonsspital, dem Rundbuck (He16), ist ein Deckenschotterrest vorhanden, dessen Mächtigkeit $5 \mathrm{~m}$ kaum übersteigen dürfte. Seine Untergrenze liegt wahrscheinlich bei etwa $500 \mathrm{~m}$ ü.M.

Entlang des E-Randes des Engewaldes sind zwischen dem Ölberg bei Schaffhausen und der Hohfluh bei Neuhausen Tiefere Deckenschotter verbreitet. Aufschlüsse sind vor allem im südlichen Bereich bis auf rund $490 \mathrm{~m}$ hin- unter vorhanden. Die Einregelung der flachen Gerölle lässt auf eine Paläoströmung nach W schliessen (He11).

Ein Relikt verkitteter Schotter befindet sich im Bereich der Kulmination des Buechbüel im Neuhauserwald (KLH1). Die Höhenlage der Untergrenze der Schotter kann anhand der existierenden Aufschlüsse (zwei ehemalige Kiesgruben, 687.050/282.275 und $687.125 / 282.475$ ) auf wenig unter $550 \mathrm{~m}$ ü.M. geschätzt werden. Die Mächtigkeit der Ablagerung beträgt demnach etwa $15 \mathrm{~m}$. Die Einregelung der flachen Gerölle belegt eine Paläoströmung nach WSW.

\section{Hasenberg-Spitz, Rechberg, Gegend um Waldshut (Verwendete Literatur: VERDERBER (1992), Hofmann (1981), Frei 1912))}

Die Deckenschotter des Gebietes HasenbergSpitz grenzen im SE an die Gesteine des Doggers an. Sie lagern in diesem Bereich möglicherweise einer rinnenrandlichen Verflachung mit Basis um 465-470 m ü.M. auf, was auch für die Schotter der Kniebreche östlich des Hasenbergs gilt. Gegen NW senkt sich die Basis dann um rund 20-30 m ab. Aufschlüsse östlich des Hofes Haslach und beim Hungerbüel zeigen, dass die Basis auf 445 m ü.M. liegen könnte. Am W-Ende des Hasenbergs müsste sie sich gar unter $440 \mathrm{~m}$ ü.M. befinden (z.B. KLT5).

Die Auflagerungshöhe der Deckenschotter vom Rechberg kann entlang des Südhanges auf ca. 435-440 m ü.M. gut abgeschätzt werden (Auflagerung auf Dogger). Die tiefstgelegenen Schotteraufschlüsse befinden sich im Gebiet Winterhalden südlich von Willmendingen (KLT14, KLT14) auf rund $425 \mathrm{~m}$ ü.M., also auf der nördlichen Seite des Hügels. Weiter gegen N steigt die Sohle allmählich an, und etwa auf der Höhe von Schwerzen enden die Schotter entlang einem etwa E-W streichenden alten Talhang. Eine Rohstoffbohrung (671.575/276.750; R/H: 34'54'320/52'77'830) erreichte den Opalinus-Ton auf $432 \mathrm{~m}$ ü.M. Aus diesen Angaben lässt sich eine leicht rinnenförmige Eintiefung der Deckenschotterbasis in 


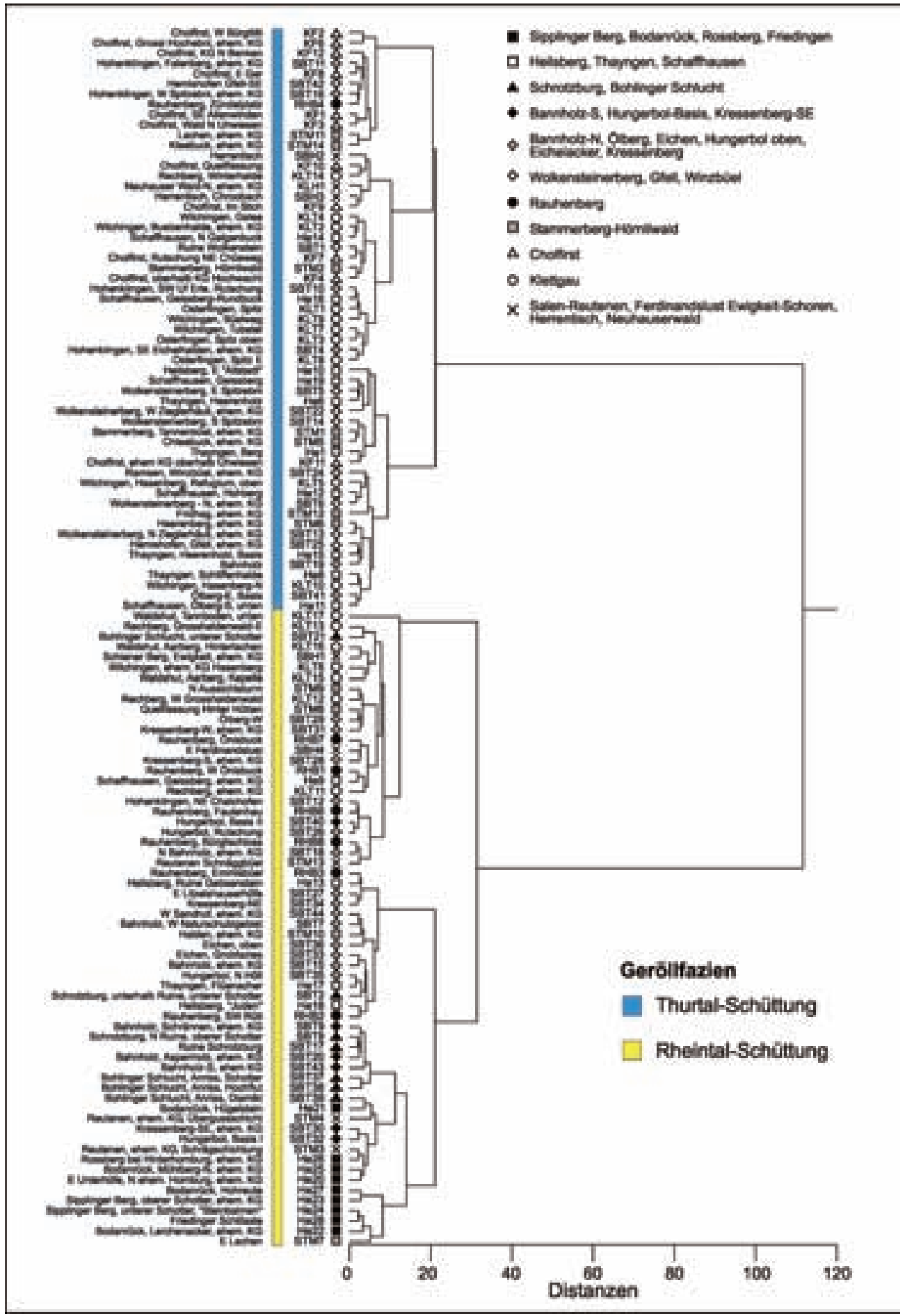

Abb. 9: Dendrogramm der Clusteranalyse aller Geröllzählungen aus dem Untersuchungsgebiet.

Fig. 9: Cluster analysis dendrogram of all gravel component countings in the study area. 


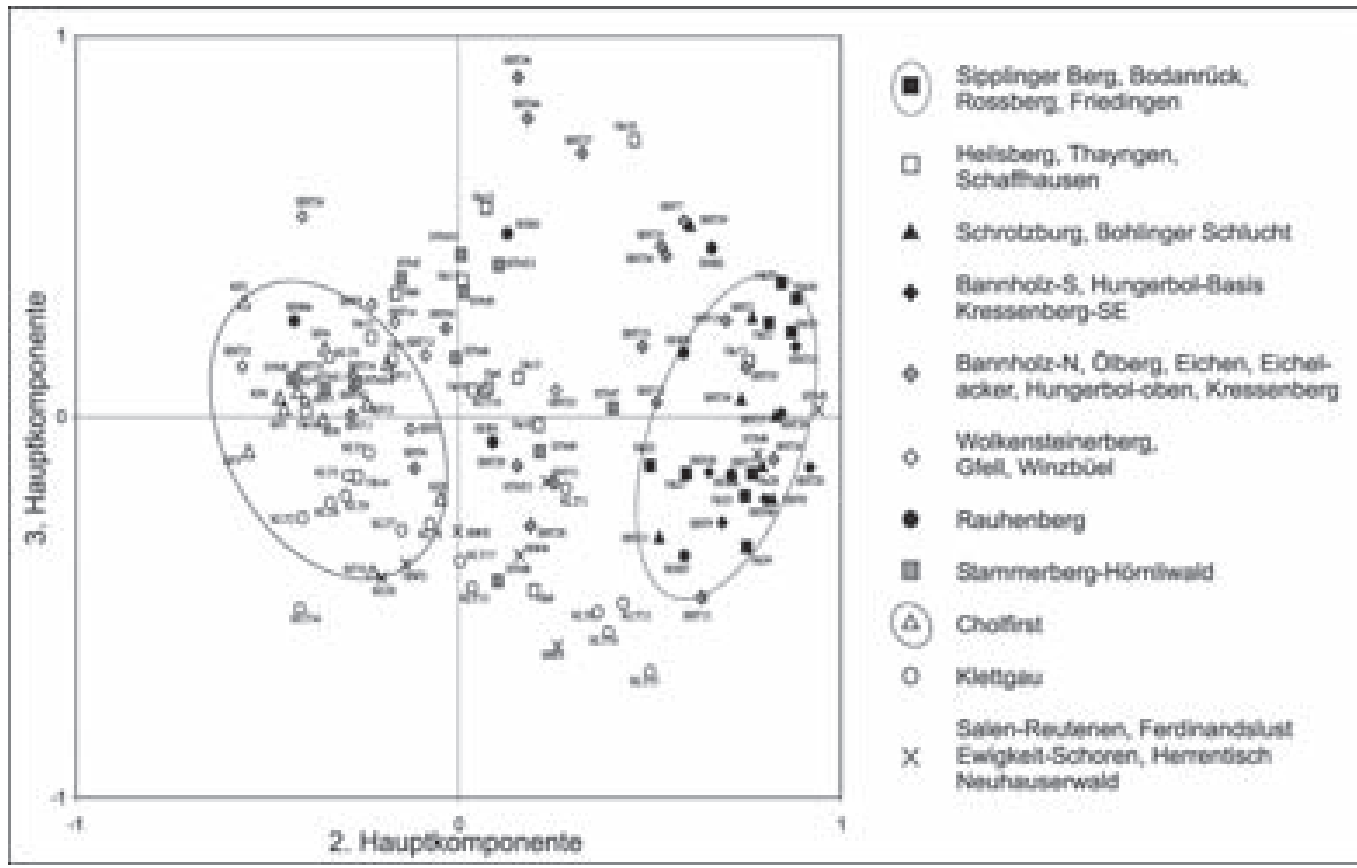

Abb. 10: Punktwolkendarstellung der Hauptkomponentenanalyse aller Geröllzählungen aus dem Untersuchungsgebiet. Dargestellt sind die zweite und dritte Hauptkomponente.

Fig. 10: Scatter plot of the principal component analysis of all gravel component countings in the study area. The $2^{\text {nd }}$ and $3^{\text {rd }}$ principal components are illustrated.

die mesozoischen Gesteine ableiten, mit einer Rinnenachse ungefähr entlang dem Hügelzug Rechberg-Sommerhalde.

Nordöstlich von Waldshut können drei Deckenschotter-Einheiten unterschieden werden. Die höchstgelegenen Schotter (TannbodenOben) weisen einen aberranten Habitus auf. Sie sind relativ grobkörnig ausgebildet mit außergewöhnlich grossen Hohlräumen (Durchmesser bis $20 \mathrm{~cm}$ ). In der sandigen Matrix kommen zahlreiche rote und braunrötliche Tonsteinklasten vor, bei denen es sich um aufgearbeitetes Lokalmaterial aus dem Keuper handeln dürfte. Diese Schotter lagern auf rund $450 \mathrm{~m}$ ü.M. dem Oberen Muschelkalk auf (Aufschluss 659.450/275.750; R/H: 34'42'150/52/77'125). Die Schotter vom Tannboden-Unten (KLT17) dürften auf rund $420 \mathrm{~m}$ ü.M. dem Oberen $\mathrm{Mu}-$ schelkalk auflagern, wobei dies wahrscheinlich nicht der Höhe der Rinnenbasis entspricht, welche noch einige Meter tiefer zu vermuten ist. Die Schotter des Aarbergs (KLT15, KLT15, KLT16) lagern auf 405-410 m ü.M. dem Mesozoikum auf.

\section{Resultate der}

sedimentpetrographischen Untersuchungen

\subsection{Geröllzählungen}

Das Dendrogramm der Clusteranalyse (Abb.9) zeigt eine Gliederung der Proben in zwei Cluster. Eine Aufgliederung der Proben nach ihrer geographischen Herkunft zeigt, dass alle Proben aus dem Hegau östlich und nördlich des Schiener Bergs im untersten Teil des unteren Clusters zu finden und untereinander sehr ähnlich sind. Sehr ähnlich sind auch die Proben aus dem Gebiet Schrotzburg-Bohlinger Schlucht sowie jene von Bannholz-S, Hungerbol-Basis und Kressenberg-SE. Die Proben vom Cholfirst liegen im obersten Abschnitt des oberen Clus- 


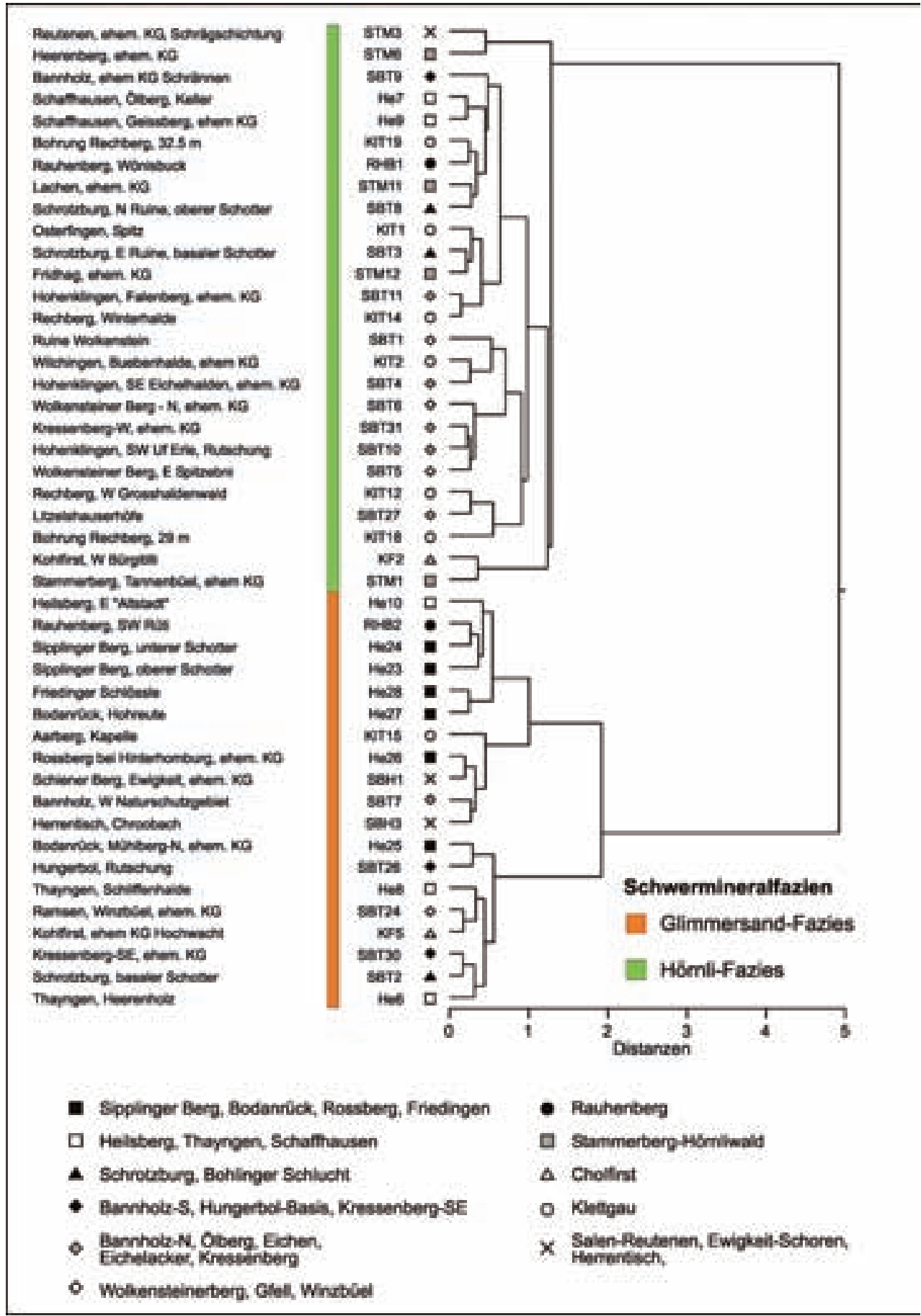

Abb. 11: Dendrogramm der Clusteranalyse aller Schwermineralzählungen aus dem Untersuchungsgebiet.

Fig. 11: Cluster analysis dendrogram of all heavy mineral countings in the study area. 
ters, wo sie mit Proben vom Stammerberg und vom westlichen Teil des Schiener Bergs vergesellschaftet sind. Die restlichen Proben vom Schiener Berg sind vorwiegend im unteren Cluster vertreten, während im oberen die meisten Proben aus dem Klettgau und dem westlichen Hegau (inkl. Gebiet um Schaffhausen) vertreten sind. Eine Probe (STM7, zuunterst im Dendrogramm) passt nicht in dieses grobe Bild, worauf unten eingegangen wird.

Die Hauptkomponentenanalyse (Abb. 10) zeigt ein sehr ähnliches Bild, wobei die Proben aus dem östlichen Hegau und diejenigen vom Cholfirst gewissermassen die Endglieder einer Mischreihe darstellen. Die erwähnte Probe STM17, welche eine aberrante Einordnung im Dendrogramm aufweist, wurde von der Hauptkomponentenanalyse in den Übergangsbereich der beiden Endglieder der Mischreihe gestellt. Diese statistische Aufgliederung des Datenmaterials erlaubt es, zwei Geröllfazien zu indetifizieren. Die eine ist im östlichen Hegau am klarsten ausgebildet, die andere auf dem Cholfirst. Der augenfälligste Unterschied der beiden Fazien liegt im Dolomitgehalt. Während er bei den Proben aus dem Hegau nur wenige Prozente beträgt, liegt er bei jenen vom Cholfirst bei mindestens 20\% (Maximum 37\%). Dieser klare Unterschied beruht höchstwahrscheinlich auf der Zufuhr von aufgearbeitetem Geröllmaterial aus den Nagelfluhen des tertiären Hörnli-Schuttfächers, welche sich durch einen hohen Anteil an Dolomitgeröllen auszeichnen. In Anlehnung an die heutigen Talverhältnisse in der Nordostschweiz sollen diese beiden Geröllfazien als Rheintalschüttung (v.a. östlicher Hegau) bzw. Thurtalschüttung (v.a. Cholfirst) bezeichnet werden.

\subsection{Schwermineralzählungen}

Das Dendrogramm der Clusteranalyse (Abb. 11) zeigt eine Aufteilung in zwei Gruppen. Eine Aufgliederung der Proben nach ihrer geographischen Herkunft zeigt, dass alle Proben aus dem Hegau östlich und nördlich des Schiener Bergs im unteren Cluster zu finden sind, ebenso die Proben vom Buechberg bei Thayngen und Heilsberg bei Eberfingen sowie die Proben aus den Höheren Deckenschottern vom Schiener Berg. Die Proben vom Stammerberg einschließlich derer vom Seerücken (Gebiet von Reutenen) liegen sämtliche im oberen Cluster. In beiden Clustern vertreten sind Proben aus den Tieferen Deckenschottern vom Schiener Berg, vom Cholfirst, vom Rauhenberg und aus dem Klettgau. Die Proben aus dem südwestlichen Teil des Schiener Bergs sind jedoch sämtliche im oberen Cluster vertreten.

Die beiden im Dendrogramm der Clusteranalyse abgetrennten Probengruppen unterscheiden sich vor allem im Granatgehalt. Während die Proben im unteren Cluster Granatgehalte von rund 60 bis gegen $88 \%$ aufweisen, liegen diejenigen der Proben im oberen Cluster deutlich darunter. Bezüglich der Gehalte an ultrastabilen Mineralien sind keine Auffälligkeiten zu erkennen. Anhand dieser statistischen Aufteilung und dem Vergleich der wesentlichsten Charakteristiken der im Untersuchungsgebiet verbreiteten Molassegesteine werden zwei Schwermineralfazien unterschieden: die Glimmersandund die Hörnli-Fazies (vgl. Kapitel 2.3).

\section{Stratigraphische Synthese}

Wie oben ausgesagt, stellt der Schiener Berg sozusagen das Typusgebiet für die in der vorliegenden Arbeit untersuchten Deckenschotter dar. Aus diesem Grund - und wegen der ausgeprägten Komplexität der Verhältnisse - wird dieses Gebiet als erstes besprochen. Ebenfalls separat besprochen werden die Verhältnisse im Gebiet Stammerberg-Hörnliwald.

\subsection{Schiener Berg}

Die Höheren Deckenschotter lassen sich anhand der vorliegenden Kenntnisse stratigraphisch nicht weiter aufgliedern. Die geröllpetrographischen Daten zeigen (Abb. 9, 10), dass vermutlich zwei verschiedene Schüttungssysteme an der Ablagerung beteiligt waren. Während im NE die Rheintalschüttung deutlich überwog, zeigen die Schotter westlich von Ferdinandslust einen verstärkten Einfluss der 
Thurtalschüttung, welcher offenbar im Bereich Herrentisch sogar dominant war. Ob diese Verhältnisse auf die Konfluenz der beiden Entwässerungssysteme im Bereich des Schiener Bergs schließen lassen, oder ob eine Heterochronie der Ablagerungen besteht, kann anhand der vorliegende Kenntnisse nicht entschieden werden. Bezüglich der Schwermineralien gehören alle Höheren Deckenschotter vom Schiener Berg der Glimmersand-Fazies an.

Am N-Rand des Schiener Bergs kommt der Rest einer relativ engen Rinne vor. Es scheint sich dabei um das Relikt einer Flussschleife zu handeln, die zu einem alten Tal(-System?) gehörte, welches nördlich des Schiener Bergs im heutigen Hegau verlief (Abb. 4, 15). Die Rinnenbasis liegt auf rund $585 \mathrm{~m}$ ü.M., was eine Tieferlegung des Gewässernetzen um mindestens $80 \mathrm{~m}$ gegenüber den Höheren Deckenschottern belegt. Die Sedimentfüllung der Rinne ist in zwei Phasen entstanden. Während der ersten Phase gelangten ausschließlich glazifluviale Schotter der Rheintalschüttung zur Ablagerung (Bohlingen-Schotter). Hernach folgte ein Zeitabschnitt mit ruhiger Sedimentation und vielleicht temperierten Verhältnissen, der gewisse pedogenetische Vorgänge ermöglichte. In der zweiten Phase fand ein markanter Eisvorstoß statt, dokumentiert durch diamiktische Gletscherablagerungen (Schrotzburg-Till). Ihre Fazies lässt auf die Entstehung in einer Stausituation schließen. Bei seinem Rückzug hinterließ der Gletscher die gletschernah abgelagerten Schrotzburg-Schotter.

Im südlichen Bereich des Schiener Bergs liegt ein Mosaik von verschiedenen Rinnen vor, welches als Ganzes eine Absenkung des Gewässernetzes um rund $100 \mathrm{~m}$ gegenüber den Höheren Deckenschottern dokumentiert (Abb. 4, 14). Insgesamt sind drei ehemalige Rinnen vorhanden, die wahrscheinlich in zwei Phasen entstanden. Die Rinnen Bannholz-HungerbolKressenberg und Hohenklingen-Kressenberg, dürften ihre Basis etwas unterhalb von $570 \mathrm{~m}$ ü.M. haben, wogegen die Rinne WolkensteinWinzbüel eine Basis unter 550 m ü.M. aufweist (nach SchreIner 1991 ca. 540 m ü.M.). Die Rinne Bannholz-S-Hungerbol-Kressenberg wird gegenüber dem nördlich angrenzenden Gebiet durch einen Felssporn abgegrenzt, so dass dort vielleicht eher von einer höher gelegenen Rinne als von einem Felsplateau gesprochen werden muss. Wie diese Talmorphologie entstand - ob zuerst eine breite Talung gebildet wurde, in diese sich später die engeren Rinnen weiter eintieften oder ob der Ablauf umgekehrt war - muss vorläufig offen bleiben.

Die in Kapitel 3.2 mehrfach erwähnte markante Blockfazies im oberen Abschnitt der Deckenschotter vom Bannholz, Sandhof, Hungerbol, Litzelshausen, Ölberg-Eichen und Kressenberg (Untergrenze auf etwa 600-610 m ü.M.) macht es wahrscheinlich, dass alle diese Relikte zum gleichen Gesteinskörper gehören, zumindest oberhalb von rund $600 \mathrm{~m}$ ü.M. Die Blockfazies klingt sowohl gegen SW als auch gegen WNW (also in der rekonstruierten Strömungsrichtung) allmählich aus. Wahrscheinlich wurden diese Sedimente von einem Gletscher aus dem Bereich unmittelbar südöstlich des Schiener Bergs entlang dem N-Rand der Rinnen geschüttet. Später drang das Eis über die Schotter hinweg nach NW vor. Dieser Umstand wird durch die offenbar nur wenig transportierten, also in Gletschernähe abgelagerten Kiese und Diamikte der Grube westlich des Sandhofs (709.950/282.400) sowie durch das verbreitete Vorkommen von (z.T. zahlreichen) zerdrückten Geröllen in matrixfreien Lagen der groben Schotter impliziert. Der Gletschervorstoß reichte möglicherweise bis in den $\mathrm{E}$ des Rauhenbergs, wo ebenfalls zerdrückte Gerölle vorkommen.

Diese genetischen Zusammenhänge haben auf die Rekonstruktion der Felsoberfläche einen wesentlichen Einfluss, indem die tiefe Lage der Felsoberfläche im südwestlichen Bereich des Hungerbols als Teil einer Rinne erklärt werden muss, die westlich vom Bannholz verläuft. Demnach könnten die Schotter vom Bannholz$\mathrm{S}$ Teil der gleichen Rinnenfüllung sein. Diese Interpretation wird durch die Petrographie der basalen Schotter unterstützt, gehören doch sowohl die unteren Abschnitte der Schotter von Bannholz-S als auch jene vom Hungerbol und dem östlichsten Kressenberg zur Rheintal- 


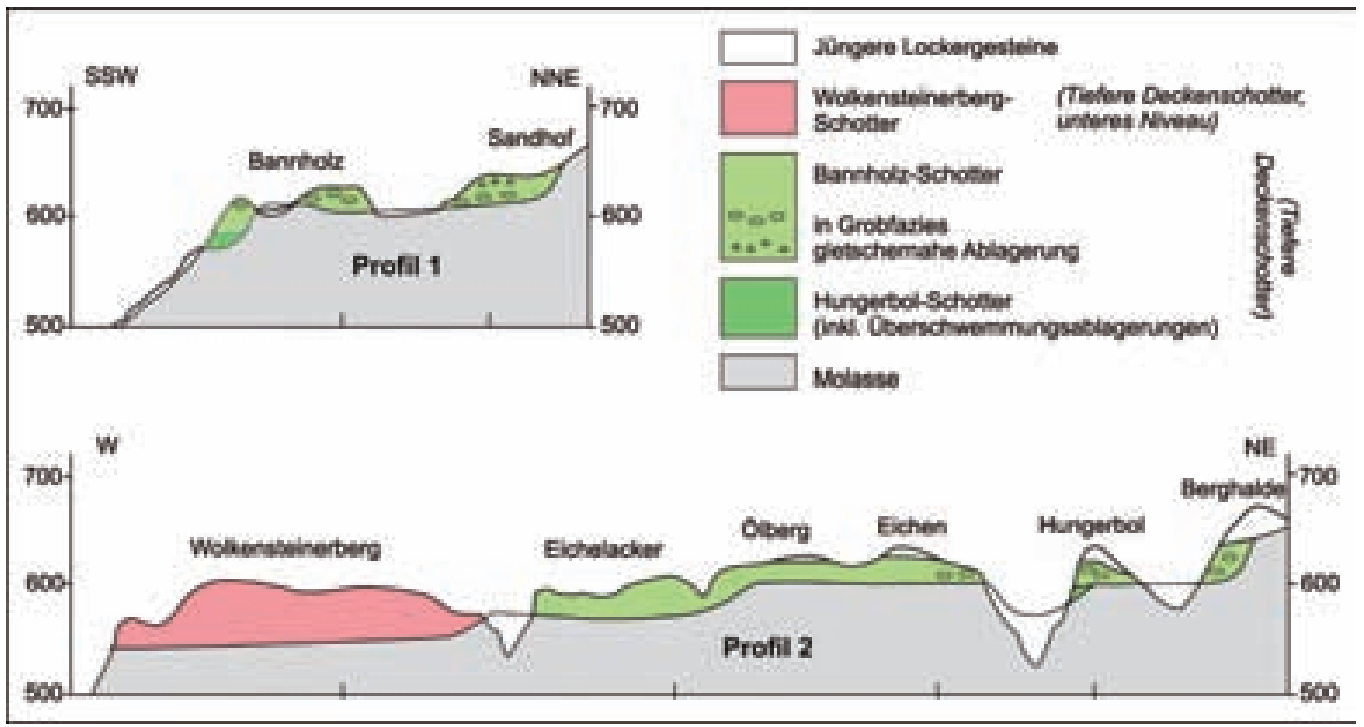

Abb. 12: Geologische Schnitte durch die Deckenschotter des Schiener Bergs (Lage der Profillinien vgl. Abb. 4).

Fig. 12: Geological sections across the Schiener Berg Deckenschotter occurrences (trace of sections: see Fig. 4).

schüttung; dies im Gegensatz zu den erwähnten blockigen Schottern, welche als Mischfazies zu deuten sind (Abb. 9, 10).

Die geröllpetrographische Gliederung der Deckenschotter vom Hungerbol wird durch das Auftreten einer Abfolge von Überschwemmungssedimenten zwischen den basalen Schottern und der Blockfazies bestätigt. Die Schneckenreste enthaltenden Sedimente entstanden während einer Phase ohne direkten Gletschereinfluss. Die Entkalkung der Sedimente im obersten Profilteil deutet auf temperierte Verhältnisse während des betreffenden Zeitabschnittes hin.

Die Schotter der Rinne Hohenklingen-Kressenberg gehören mehrheitlich der Thurtalschüttung bzw. der Hörnli-Fazies an. Der in Abb. 4 dargestellte, betont gegen $\mathrm{N}$ gerichtete Verlauf wird durch die Petrografie der basalen Schotter des südlichen Bereichs des Kressenbergs bedingt. Diese gehören nicht der Rheintalschüttung an, wie ihre Äquivalente im Osten des Kressenbergs, sondern zeigen deutlich den Einfluss der Thurtalschüttung.

Die aus Gerölleinregelungen ermittelten $\mathrm{Pa}$ läoströmungsrichtungen in den oberen $\mathrm{Ab}$ schnitten der einzelnen Deckenschottervor- kommen deuten darauf hin, dass die Schotter der Rinne Wolkenstein-Winzbüel diejenigen der beiden anderen Rinnen durchschneiden. Dies lässt auf ein jüngeres Alter der Rinne Wolkenstein-Winzbüel schließen. Bestätigt wird dieser Schluss durch die Zusammensetzung der Schotter, gehen sie doch eindeutig auf die Thurtalschüttung zurück; ein Einfluss der Rheintalschüttung ist kaum festzustellen. Die dominierende Zugehörigkeit der Schwermineralproben zur Hörnli-Fazies bestätigt diese Interpretation.

Zusammenfassend sind die Deckenschotter des Schiener Bergs als Sedimente von mindestens vier Ablagerungsphasen zu deuten. Als älteste Sedimente können die Höheren Deckenschotter im Kuppenbereich des Gebietes gelten. Hernach fand eine (vielleicht mehrphasige) Tieferlegung des Entwässerungsnetzes statt, welche sowohl südlich wie nördlich des Schiener Bergs eine Tallandschaft entstehen ließ. Im S existierten zwei Rinnen mit angrenzenden Verflachungen. Diese Landschaft wurde in zwei Phasen überschottert. Die Aufschotterung im N betrug mindestens $30 \mathrm{~m}$. Im S sind die entsprechenden Ablagerungen beim Hungerbol in nur 
wenigen Metern Mächtigkeit erhalten geblieben; Im Gebiet Bannholz-S sind sie mindestens $15 \mathrm{~m}$ mächtig. Es folgte ein Zeitabschnitt mit reduzierter Ablagerungsaktivität und wahrscheinlich temperierten Verhältnissen. Anschließend entstanden erneut glazifluviale Schotter, die gegen oben in eine Blockfazies übergehen und vom Eis überfahren wurden. In der nördlichen Talung ist dieser Vorstoß durch glazigene Ablagerungen und später entstandene gletschernahe Schottern dokumentiert. Es folgte eine erneute Erosionsphase, welche die Rinne Wolkensteinerberg-Winzbüel entstehen ließ. Diese wurde während einer nachfolgenden Vereisungsphase mit glazifluvialen Schottern aufgefüllt.

\subsection{Stammerberg-Hörnliwald}

Die Deckenschotter der Hochfläche vom Gebiet Stammerberg-Hörnliwald stellen wahrscheinlich eine einzige morphostratigraphischen Einheit dar. Sie wurden auf einem Felsrelief abgelagert, das auf die Existenz von zwei sich im Gebiet des Stammerbergs vereinigende flachen Rinnen schliessen lässt. Diese beiden Elemente waren durch eine Felshochzone getrennt, die im NE von Nussbaumen noch andeutungsweise erhalten ist (Abb. 7)

Die von früheren Autoren gemachten Angaben zum lithologischen Aufbau der Deckenschotter der Hochfläche Stammerberg-Hörnliwald lassen auf eine zweiphasige Akkumulation schliessen. So postulierte BECK (1933) zwei Vorstöße, den älteren Herdern-Vorstoß und den jüngeren Stammheimer Vorstoß. Wegen der sehr beschränkten Aufschlussverhältnisse konnten diese beiden Vorstöße mit den für die vorliegende Arbeit durchgeführten Untersuchungen weder auf sedimentologischen noch petrographischen Weg nachvollzogen werden; für die stratigraphische Interpretation muss also auf den Literaturangaben basiert werden. Bisher durch eine einzige Bohrung belegt, kann im Raum nordwestlich von Nussbaumen die Existenz einer jüngeren Einheit der Deckenschotter vermutet werden. Diese entstand im Bereich eines glazialen Beckens. Die räumliche Verteilung der bekannten Fels- und Decken- schotteraufschlüsse lässt geometrisch nur eine nach S offene Beckenstruktur zu. Dementsprechend wäre also mit einem Eisvorstoss aus dem Bereich des heutigen Thurtales zu rechnen. Das Schmelzwasser, welches die erbohrten Schotter hinterliess, floss daher wahrscheinlich gegen $\mathrm{N}$ $a b$, also ungefähr in Richtung Stein am Rhein (Abb. 13).

\subsection{Gesamtes Untersuchungsgebiet}

Anhand von geomorphologischen und lithostratigraphischen Kriterien können im Untersuchungsgebiet drei morphostratigraphische Einheiten unterschieden werden (vgl. Abb. 13). Sie werden in Anlehnung an die in der früheren Literatur verwendete Nomenklatur wie folgt bezeichnet:
(a) Höhere Deckenschotter
(b) Tiefere Deckenschotter
(c) Tiefere Deckenschotter, unteres Niveau

Die von Schreiner (1991) und Verderber (1992) eingeführte Bezeichnung Mittlere Deckenschotter wird nicht übernommen. Dies ist wie folgt zu begründen: Die Mittleren Deckenschotter wurden von SCHREINER (1991) mit der Haslach-Eiszeit des östlichen Rheingletschergebietes (SCHREINER \& EBel 1981) korreliert. In der so bezeichneten morphostratigraphischenEinheit des Schiener Berges liegen jedoch Hinweise vor, dass sie Ablagerungen aus mindestens 2 Phasen (vermutlich Eiszeiten) beinhaltet. Ausserdem wird die Abgrenzung der beiden tieferen morphostratigraphischen Einheiten in der vorliegenden Arbeit im Detail anders vorgenommen als von SchreIner (1991). Stattdessen werden die für die Kartierung von Blatt Zurzach des Geologischen Atlas der Schweiz 1:25.000 (BitTerLI et al. 2000) verwendete Gliederung und Bezeichnung übernommen.

\subsubsection{Höhere Deckenschotter}

Zu dieser Einheit werden die Deckenschottervorkommen Ferdinandslust, Ewigkeit, Herren- 
tisch (vom Schiener Berg), Salen-Reutenen, Neuhauserwald und Tannboden-Oben (bei Waldshut) gestellt. Allerdings bleiben dabei verschiedene Fragen offen. Das Vorkommen vom Neuhauserwald und vom TannbodenOben (bei Waldshut) könnten von der geomorphologischen Position und der petrographischen Zusammensetzung her auch zu den Tieferen Deckenschottern gestellt werden (vgl. unten).

Die altersmäßige Einstufung der Schotter von Salen-Reutenen ist seit langem in Diskussion (Früh (1910), PencK \& BRÜCKNer (19011909), Frei (1912b), Geiger (1943), Hantke (1962), Krayss \& Keller (1994)). Mal wurden sie als Höhere Deckenschotter interpretiert, mal als junge (letzteiszeitliche) Bildungen. Das Vorkommen weist, sofern es sich tatsächlich um einen einzigen Schotterkörper handelt, eine deutliche Gliederung seiner Auflagerungsfläche auf. Die tiefste bekannte Höhe ihrer Auflagerungsfläche (ca. $660 \mathrm{~m}$ ü.M.) ist angesichts der (paläo-)geographischen Lage der Lokalität (im Anströmbereich des Schiener Bergs) eigentlich zu tief um geomorphologisch - ohne Zuhilfenahme von tektonischen Argumenten (vgl. Kapitel 6.5) - in den Kontext der übrigen Höheren Deckenschotter gestellt werden zu können. Sollte es sich allerdings um zwei getrennte Gesteinskörper handeln, wovon der östliche eine Basishöhenlage von ca. 685 m ü.M. aufweisen würde (ZAUGG 2001), könnte dieser geomorphologische mit den Vorkommen vom Schiener Berg in Zusammenhang gebracht werden. Beim tiefer liegenden, westlichen Schotter (Heidenland) würde es sich dann um eine jüngere, vorläufig nicht näher zu datierende Bildung handeln.

Unter der Voraussetzung, dass die Deckenschotter von Salen-Reutenen zur gleichen Einheit wie die Relikte vom Schiener Berg zu stellen sind (vgl. auch 6.4), kann folgende Rekonstruktion der Ablagerungsverhältnisse gemacht werden:

Die Höheren Deckenschotter wurden möglicherweise von zwei getrennten Lappen des Bodensee-Rheingletschers geschüttet. Dabei entstanden die Schotter von Salen-Reutenen im Bereich zwischen den beiden Lappen (was die deltaartigen Schrägschichtungen erklären könnte). Im NE lieferte ausschließlich der im Bereich des heutigen Untersees liegende Rheintallappen Geröllmaterial, während weiter im W der Einfluss der Thurtalschüttung bemerkbar ist. So wurden die Deckenschotter von Ewigkeit vom Rheintallappen geschüttet, während die Vorkommen von Ferdinandslust und Herrentisch den Einfluss der Thurtalschüttung klar aufzeigen. Das gilt auch für die Deckenschotter vom Neuhauserwald. Somit könnte von einer damaligen Gletscherausbreitung bis mindestens in den Raum Salen-Reutenen ausgegangen werden. KraYsS \& KeLLER (1994) gehen alternativ von einer entlang dem südwestlichen Gletscherrand verlaufenden Entwässerungsrinne aus, welche im obigen Zusammenhang für die Zufuhr von Material der Thurtalschüttung verantwortlich sein könnte. Im Rahmen dieses Modells wären die Schotter von Salen-Reutenen möglicherweise als Bildungen im randlichen Bereich des Gletschers, also im Übergang zum angrenzenden Molasse-Hochgebiet zu interpretieren, wo zeitweilige Stausituationen denkbar wären.

\subsubsection{Tiefere Deckenschotter}

Die morphostratigraphisch definierte Einheit der Tieferen Deckenschotter (von SchreINER (1991) als Mittlere Deckenschotter bezeichnet) weist eine charakteristische Gliederung der Felsbasis auf. Sie umfasst mehrere Rinnen und angrenzende flache Felsplateaus. Solche Rinnen sind auf dem Sipplinger Berg (Basis $<650$ m ü.M.), im Gebiet Schrotzburg - Bohlinger Schlucht (ca. 585 m ü.M.), Bannholz-S bis Hungerbol (<570 m ü.M.), Hohenklingen-Kressenberg ( $<570$ m ü.M.), Rauhenberg ( $<550$ m ü.M.) und oberhalb von Stammheim zu erkennen (ca. 565 m ü.M.). Felsplateaus liegen vor auf dem Sipplinger Berg (ca. $670 \mathrm{~m}$ ü.M.), Bodanrück (650 m ü.M.), Bannholz-N (ca. 610 m ü.M.), Ölberg-Eichen (ca. $600 \mathrm{~m}$ ü.M.) sowie auf dem östlichen Teil vom Stammerberg-Hörnliwald (ca. 590-600 m ü.M.). Mit einer Auflagerungshöhe von rund $550 \mathrm{~m}$ 
ü.M. (Felsplateau) könnte auch das vorläufig zu den Höheren Deckenschottern gestellte Vorkommen vom Neuhauserwald (vgl. oben) zur den Tieferen Deckenschottern gehören.

Die Zuweisung der Deckenschotter vom Rauhenberg $\mathrm{zu}$ den Tieferen Deckenschottern beruht vor allem auf der petrographischen Zusammensetzung der Ablagerungen. Sie gehören größtenteils der Rheintalschüttung an, wobei jedoch auch eine gewisse Beteiligung der Thurtalschüttung nachzuweisen ist. Diese Schotter zur nächst tieferen Einheit zu stellen (Kap. 5.3.3), ist rein geomorphologisch zwar möglich. Dann müssten sie aber - wie die Ablagerungen der Rinne Wolkensteinerberg-Winzbüel - petrographisch der Thurtalschüttung angehören (vgl. unten).

Die Sedimente wurden in mindestens zwei Phasen abgelagert, welche durch einen Zeitabschnitt mit reduzierter Ablagerungsaktivität und vermutlich temperierten Verhältnissen getrennt waren. Für die erste Phase kann eine Gletscherposition im Südosten des Hörnliwalds angenommen werden (Herdern-Vorstoß, BECK 1933), allenfalls können auch die Vorkommen vom Bodanrück (gletschernahe Entstehung der Schotter) und die Diamikte vom Sipplinger Berg wegen ihrer relativ proximalen Position (bezüglich dem St. Galler Rheintal) zu diesem Vorstoß gestellt werden.

Die zweite Phase ist durch einen Gletschervorstoß gekennzeichnet, der den Schiener Berg zum größten Teil überfuhr und auf dem Stammerberg bis weit im W nachweisbar ist (Stammheimer Vorstoß, BECK 1933). Einige zerdrückte Gerölle deuten darauf hin, dass auch der Rauhenberg zum Teil noch überfahren wurde, was die Zuteilung dieses Vorkommens zu den Tieferen Deckenschotter stützt. Damit kann eine damalige Gletscherausdehnung angenommen werden, welche einige Kilometer über die von Krayss \& Keller (1994) angegebene Eisgrenze hinaus reichte. Nördlich vom Schiener Berg stieß ein zweiter Gletscherlappen nach W vor und lagerte die Diamikte und gletschernahen Schotter von Bohlinger Schlucht und Schrotzburg ab.

\subsubsection{Tiefere Deckenschotter, unteres Niveau}

Auf dem Schiener Berg und vermutlich auch im Gebiet Stammerberg-Hörnliwald ist eine dritte morphostratigraphische Einheit abgrenzbar, die Tieferen Deckenschotter, unteres Niveau. Auf dem Schiener Berg durchschneidet die Rinne Wolkensteinerberg-Winzbüel die Tieferen Deckenschotter. Sie verläuft fast S-N. Die möglichen Deckenschotter im Bereich des glazialen Beckens vom Stammerberg deuten auf eine Entwässerung nach $\mathrm{N}$ hin, womit sie geomorphologisch zwanglos mit den Ablagerungen der Rinne Wolkensteinerberg-Winzbüel in Zusammenhang zu bringen wären.

Weitere Vorkommen, die anhand ihrer Auflagerungshöhe dieser Einheit angehören dürften, sind die tieferen Vorkommen auf dem Bodanrück (Rinnenbasis $<600 \mathrm{~m}$ ü.M.), die Schotter von Rossberg-Homburg (Rinnenbasis $<590 \mathrm{~m}$ ü.M.), Friedinger Schlossberg (Rinnenbasis ca. 530 m ü.M.), Heilsberg (Rinnenbasis $<510 \mathrm{~m}$ ü.M.), Buechberg (Rinnenbasis $<515 \mathrm{~m}$ ü.M.), Berg bei Thayngen (Rinnenbasis $<515$ m ü.M.), die Deckenschotter von Schaffhausen (Rinnenbasis $<500 \mathrm{~m}$ ü.M.), Cholfirst (Rinnenbasis $<490$ m ü.M.) sowie alle Deckenschotter im Klettgau (Rinnenbasis 450-400 m ü.M.) und das Vorkommen vom Aarberg bei Waldshut (Rinnenbasis ca. $405 \mathrm{~m}$ ü.M.). Auch das isolierte Vorkommen nördlich der Rinne bei der Schrotzburg (Rinnenbasis $<605$ m ü.M.) könnte dieser Einheit angehören.

Diese Einteilung der einzelnen Vorkommen lässt die damalige Existenz von bis zu drei Schottersträngen (und damit wahrscheinlich auch drei Rinnen) erkennen. Der eine führte vom Überlinger See nördlich des Schiener Bergs nach Schaffhausen und erhielt einen $\mathrm{Zu}$ fluss vom Bodanrück her. Der zweite verlief vermutlich vom glazialen Becken des Stammerbergs her kommend am westlichen Rand des Schiener Bergs entlang nordwärts in den Bereich des Heilsbergs, wo sie in den vorher erwähnten Strang mündete. Alle Deckenschottervorkommen unterhalb vom Heilsberg zeigen deutlich den Einfluss der Thurtalschüttung, 


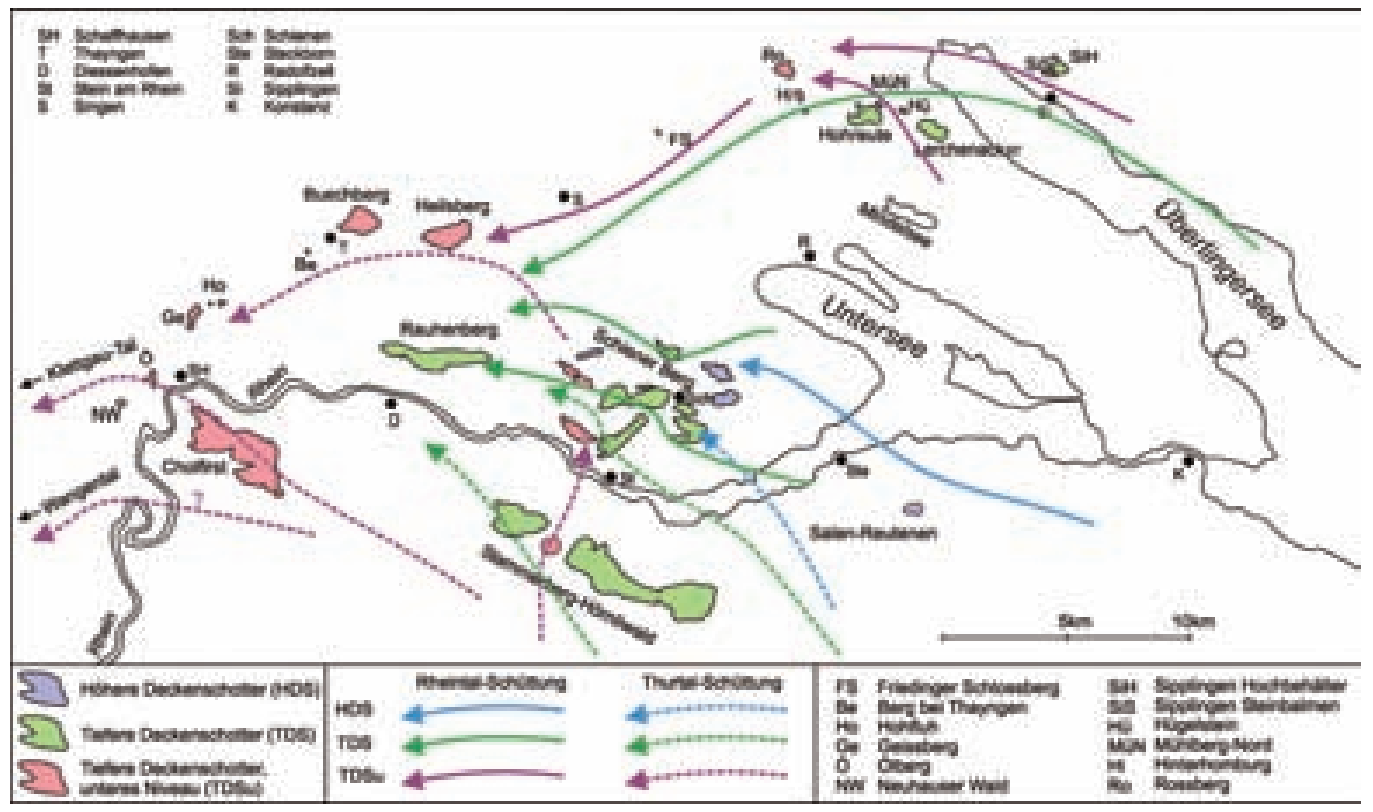

Abb. 13: Verbreitung der verschiedenen Deckenschottereinheiten im östlichen Teil des Untersuchungsgebietes. Verlauf von Rinnen, petrographische Fazien, Schüttungswege der Sedimente.

Fig. 13: Occurrences of Deckenschotter units in the eastern part of the study area. Channel courses, petrographical facies, transport directions of sediments. The arrows illustrate both origin and paths of the gravel components.

während diejenigen östlich davon ausschliesslich auf die Rheintalschüttung zurückgehen. Der dritte Strang verlief über das Gebiet des Cholfirsts hin zum Klettgau, wobei vielleicht ein Seitenstrang im südlichen Tel des Cholfirsts einmündete (vgl. auch Kapitel 3.4). Hier ist ausschließlich die Thurtalschüttung vorhanden. Vielleicht existierte gar noch eine vierte Rinne, welche südlich des Cholfirsts via Wangental ins Klettgau hinein verlief.

Aus diesen Befunden kann auf die Existenz von zwei individuellen Lappen des Rheingletschers geschlossen werden, welche von einer Hochzone im Bereich Seerücken - Schiener Berg voneinander getrennt waren. Die Existenz eines zwischen Seerücken und Schiener Berg liegenden Lappens kann zwar nicht ausgeschlossen werden, in diesem Fall wäre jedoch mit einer merklichen Zufuhr von Material der Rheintalschüttung in die Schotter v.a. vom Wolkensteinerberg zu rechnen, was anhand der untersuchten Proben jedoch nicht festzustellen ist. Der südliche Lappen breitete sich dabei in einem Vorläufer des Stammheimer Tales (bzw. Seebachtales) aus und versorgte zwei, evtl. drei Rinnen mit Gesteinsmaterial. Der nördliche Lappen erstreckte sich im Bereich des heutigen Überlinger- und Untersees. Er stiess dabei nördlich des Schiener Bergs nicht notwendiger Weise so weit nach W vor, wie von KRAYSS \& KeLLER (1994) angegeben wurde. Es ist eher von einer offenen Talverbindung zwischen den Deckenschotter vom Bodanrück, RossbergHomburg und Friedinger Schlossberg auszugehen.

\section{Neotektonik}

\subsection{Vorbemerkungen}

Wegen der geographischen Zergliederung der einst wesentlich ausgedehnteren Deckenschot- 
terablagerungen durch spätere Erosionsvorgänge ist eine Betrachtung der Möglichkeit der höhenmäßigen Verstellung von einzelnen Vorkommen durch neotektonische Vorgänge relevant. SChreiner (z.B. 1983) und vorher schon FREI (1912a) äusserten die Vermutung, dass insbesondere die Schotter vom Friedinger Schlossberg, aber vielleicht auch diejenigen vom Heilsberg gegenüber den übrigen Deckenschottervorkommen tektonisch abgesenkt sein könnten.

Im vorherigen Kapitel konnte aufgezeigt werden, dass eine geomorphologische Gliederung der einzelnen Vorkommen von Deckenschottern in drei morphostratigraphische Einheiten möglich ist. Es wird in der vorliegenden Arbeit bewusst darauf verzichtet, anhand der vorgeschlagenen Einteilung Tallängsschnitte und Schotterbasiskurven zu konstruieren (vgl. z.B. VERDERBER 1992), denn wegen der geringen Datendichte wäre dies zu spekulativ und die Gefahr von Zirkelschlüssen groß.

\subsection{Tektonische Übersicht}

Das Gebiet zwischen Bodensee und Schaffhausen befindet sich im Hegau-Bodensee-Graben, dessen südwestliche Begrenzung die Neuhauser Verwerfung darstellt (BIRKHÄUSER et al. 2001; Abb. 13). Der eigentliche Grabenbereich erstreckt sich zwischen Randen- und MindelseeVerwerfung. Außerhalb davon kann von einem Grabenrandbereich mit weniger ausgeprägten Verwerfungen gesprochen werden. Der Bereich mit maximaler Absenkung befindet sich etwa im Gebiet von Singen. Nordöstlich davon dominieren Verwerfungen mit einer Absenkung des linken Blockes, im SW Verwerfungen mit einer Absenkung des rechten Blockes. Die Hauptaktivität dieser tektonischen Zone lag im Miozän, in Verbindung mit vulkanischer Aktivität (Hegau-Vulkanismus). Die wichtigsten Störungslinien (v.a. die Randen-Verwerfung) scheinen gegen SE auszuklingen. NAEF et al. (1995) gehen davon aus, dass die Bruchtektonik im Bereich des Baden-Irchel-Herdern-Lineaments verschwindet. Neue Feldaufnahmen von ZAUGg (2001) deuten auf die Möglichkeit der Existenz einer SSW-NNE verlaufenden Transversalverschiebung hin, die sich etwa im Untersee östlich von Stein am Rhein erstrecken könnte, denn südlich des Bodensees sind nur kleinere Verstellungen von Gesteinskörpern bis maximal $30 \mathrm{~m}$ nachweisbar (vgl. dazu BüCHI \& MÜLLER AG, 2003). Eine solche Störung könnte im Zusammenhang mit dem nördlichen Rand des Nordschweizerischen Permokarbontroges stehen.

Es ist durchaus möglich, dass einige dieser tektonischen Elemente im Quartär reaktiviert wurden und so vielleicht einzelne Deckenschottervorkommen gegenüber anderen höhenmässig verstellt wurden. BIRKHÄUSER et al. (2001) erwähnen diesbezüglich eine postmolassische Deformationsphase, welche vorbestehende Verwerfung transpressiv (bei WNW-ESEOrientierung) bzw. transtensiv bei NW-SE- bis NNW-SSE-Orientierung) reaktiviert hätte. Die bisherigen Untersuchungen in der Nordschweiz lassen dabei allerdings auf eher kleine vertikale Versätze schließen (BIRKHäUSER et al. 2001).

Das Muster der bekannten Störungen lässt theoretisch viele Möglichkeiten von vertikalen Relativbewegungen einzelner Schollen zu, so dass es scheint, die Auflagerungshöhe der einzelner Deckenschottervorkommen habe eigentlich nur eine geringe Aussagekraft. Allerdings ist es sicher so, dass nicht für jede Störung von einer pleistozänen Aktivität ausgegangen werden muss und darf.

Wichtig ist, dass für den Schiener Berg, dessen Deckenschotter in der vorliegenden Arbeit als Typus für die untersuchten Ablagerungen verwendet werden, offenbar keine Störungen vorliegen, welche die einzelnen Schotterrelikte gegeneinander verstellt haben könnten. Demnach wird die oben vorgeschlagene lithostratigraphisch-geomorphologische Gliederung der Deckenschotter nicht in Frage gestellt.

Drei Aspekte werden im Folgenden diskutiert, nämlich die angesprochene relative Absenkung der Deckenschotter von Friedinger Schlossberg und Heilsberg, der Zusammenhang zwischen Stammerberg-Hörnliwald und Cholfirst, sowie die Höhenlage des Schottervorkommens von Salen-Reutenen. 


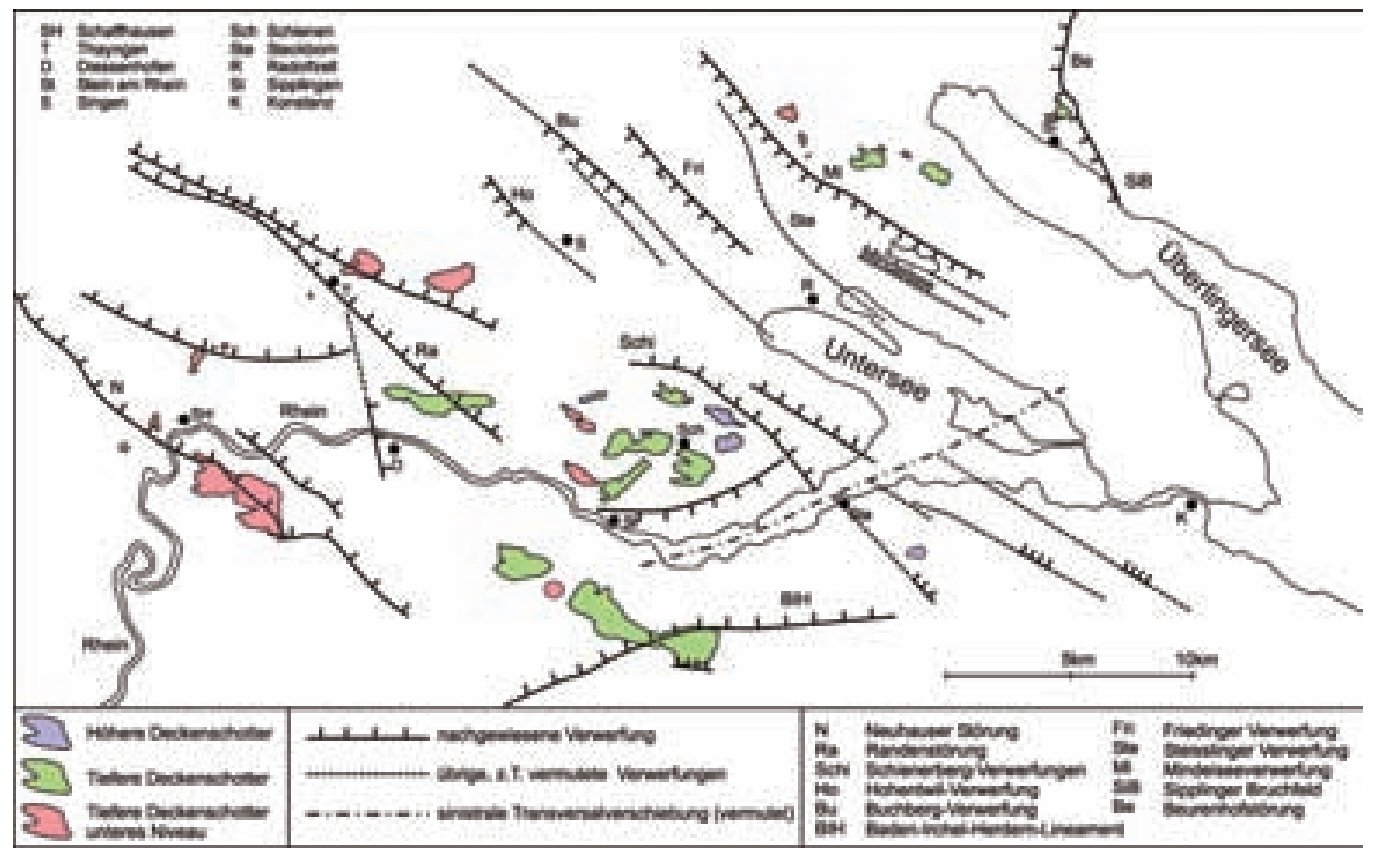

Abb. 14: Kartenskizze der Nordostschweiz und der angrenzenden süddeutschen Gebiete, mit Angabe der wichtigsten bekannten tektonischen Störungslinien und der Verbreitung von Deckenschottern (nach: BIRKHÄUSER et al. 2001, SCHrEINER 1992b, ZAUGG 2001, 2002).

Fig. 14: Geological sketch map of northeastern Switzerland and adjacent southern Germany depicting the most important tectonic lineaments and the Deckenschotter occurrences (after BIRKHÄUSER et al. 2001, SCHREINER 1992b, ZAUGG 2001, 2002).

\subsection{Friedinger Schlossberg und Heilsberg}

Zwischen dem Friedinger Schlossberg und den östlich davon gelegenen Deckenschotterresten erstrecken sich die Friedinger, Steisslinger und die Mindelsee-Verwerfung, welche gegen W zusammen eine Absenkung der Basis der Oberen Süsswassermolasse von weit über $100 \mathrm{~m}$ erkennen lassen (SCHREINER 1992b). Die in Kapitel 5.3 vorgeschlagene morphostratigraphische Einteilung der einzelnen Deckenschotterreste ergibt einen Höhenunterschied der Auflagerungsfläche zwischen den Schottern der Unteren Einheit von Rossberg-Homburg gegenüber denjenigen vom Friedinger Schlossberg von ca. 50-60 m. Diese auffällige Höhendifferenz könnte auf tektonische Absenkungen im W des Bodanrücks zurückgeführt werden. Dies widerspricht der oben gemachten Bemerkung, dass bisher eher von kleinen vertikalen
Versätzen für die postmolassische Tektonik auszugehen sei. Allerdings ist die Kinematik des NE-Randes des Hegau-Bodensee-Grabens diesbezüglich noch zu wenig genau untersucht worden.

Eine alternative Interpretation wäre, dass sämtliche der besprochenen Deckenschotter, welche östlich der Mindelsee-Verwerfung liegen, den Tieferen Deckenschottern angehören, wobei dann von einer Zunahme des Höhenunterschiedes zwischen Rinnen und angrenzenden Felsplateaus ausgegangen werden muss. Damit würde sich ein eventueller vertikaler Versetzungsbetrag grob auf etwa 20-30 m abschätzen lassen, was eher im Rahmen der erwähnten jungen Reaktivierung der Grabenverwerfungen liegt.

Bezüglich einer Absenkung von Friedinger Schlossberg und Heilsberg relativ zu den Deckenschottern des Thaynger Buchbergs beste- 
hen nach heutigen Kenntnissen keine tektonisch-strukturellen Hinweise. Allenfalls wäre von einer Absenkung des Heilsbergs gegenüber dem Friedinger Schlossberg auszugehen.

\subsection{Stammerberg und Cholfirst}

Bisher wurden die Deckenschotter der beiden Gebiete pauschal zu den Tieferen Deckenschottern gestellt (z.B. HüBSCHER 1961), obwohl eine bedeutende Höhendifferenz ihrer Auflagerungsflächen zu erkennen ist. Auf dem Stammerberg lagern die Schotter auf rund $565 \mathrm{~m}$ ü.M. der Molasse auf, während sie im SE des Cholfirsts auf etwas über $530 \mathrm{~m}$ ü.M. und NE auf etwa 510 m ü.M. dem Fels auflagern. Daraus ergäbe sich ein potenzielles Rinnengefälle von 4-6\%. Anhand der konstruierten Auflagerungsflächen der beiden Deckenschottervorkommen kann kein derart steiles Gefälle hergeleitet werden. Deshalb wurde in Kapitel 5.3 vorgeschlagen, die beiden Vorkommen zu verschiedenen morphostratigraphischen Einheiten zu stellen. Es stellt sich die Frage, ob auf Grund der bekannten tektonischen Elemente eine vertikale Verstellung der beiden Gebiete anzunehmen sei.

Anhand von Abbildung 14 ist zu erkennen, dass lediglich die Neuhauser Verwerfung und eine ihr im NE vorgelagerte (unbenannte) Struktur (vgl. auch SzEPESSY 1999) für eine allfällige Verstellung der beiden Deckenschotter in Frage kommen. Der Bewegungssinn beider Verwerfungen spricht aber klar gegen eine relative $\mathrm{Ab}$ senkung des Cholfirsts gegenüber dem Stammerberg; das Gegenteil wäre wahrscheinlicher. Aus diesem Grund wird davon ausgegangen, dass die beiden Deckenschotter tatsächlich verschiedenen morphostratigraphischen Einheiten zugehören.

\subsection{Salen-Reutenen}

Im Gebiet zwischen Salen-Reutenen und dem Schiener Berg verlaufen diverse (z.T. allerdings nur vermutete) tektonische Linien (Abb. 14). Die randlich des Schiener Bergs verlaufenden Verwerfungen sowie eine südwest- lich von Salen-Reutenen existierende Störung (BüCHI + Müller AG 2003) lassen eine relative Absenkung des Gebietes Salen-Reutenen gegenüber dem Schiener Berg grundsätzlich als möglich erscheinen. Somit wäre die Diskrepanz zwischen den Auflagerungshöhen der in beiden Gebieten vorkommenden Höheren Deckenschotter (vgl. 5.3.1) erklärbar und würde die entsprechende morphostratigraphische Einstufung des Vorkommens von Salen-Reutenen rechtfertigen. Die bestehenden Ungewissheiten bezüglich der tektonischen Gliederung des Gebietes südlich des Untersees, des Bewegungssinns der einzelnen Blöcke sowie des Zeitpunkts von Relativbewegungen lassen eine solche Schlussfolgerung allerdings nur mit grossem Vorbehalt zu.

\subsection{Folgerungen für die Stratigraphie}

Ein Vergleich der bekannten tektonischen Strukturen im Untersuchungsgebiet mit der Verbreitung und insbesondere Höhenlage von Deckenschotterrelikten zeigt, dass sich die auffällig großen Höhenunterschiede der Deckenschotter beiderseits der Mindelsee-Verwerfung durch neotektonische Vorgänge erklären lassen könnten. Eine alternative Erklärung dieses Umstandes, indem die in Kapitel 5.3.3 zu den Tieferen Deckenschotter, unteres Niveau gestellten Vorkommen von Sipplingen und RossbergHomburg als Relikte der tiefsten Rinnenfüllung der Tieferen Deckenschotter interpretiert, ist aber - mit Einschränkungen - ebenso möglich. Für das übrige Untersuchungsgebiet liegen keine Befunde vor, die eine wesentliche Anpassung der oben dargestellten morphostratigraphischen Analyse erforderlich machen würden.

\section{Korrelation mit den Deckenschottern der zentralen Nordschweiz und den frühpleistozänen Ablagerungen des süddeutschen Alpenvorlandes}

\subsection{Ausgangslage}

Es liegen zurzeit keine Datierungen für die in vorliegender Arbeit untersuchten Deckenschot- 
ter vor, welche auf diesem direkten Weg eine Korrelation mit den Vorkommen in der zentralen Nordschweiz oder im süddeutschen Alpenvorland ermöglichen würden. Somit ist eine Korrelation vorläufig nur anhand von geomorphologischen Kriterien möglich. Als Grundlage werden im Folgenden zunächst Überlegungen zur Morphogenese in den verschiedenen Gebieten und so grundsätzlich zur Korrelierbarkeit mit diesem Ansatz angestellt.

\subsection{Steuerung der Morphogenese im nordschweizerischen Mittelland}

Es wird heute von einer im Mittel stetigen Hebung des Alpenkörpers während des Quartärs ausgegangen (MüLlER et al. 2002). Der Faltenjura und der Schwarzwald zeigen eine Hebungstendenz; dazwischen dehnt sich eine nicht genau abzugrenzende Zone mit relativer tektonischer Ruhe aus. Als tektonisch aktive Zone im Unterlauf der zur Nordsee hin entwässernden schweizerischen Flüsse ist der Oberrheingraben von Bedeutung. Eine synsedimentäre Absenkung in großen Teilen des Grabens ist für das Quartär belegt. Bezüglich der Sedimente liegt dort eine generell normalstratigraphische Überlagerung vor, im Gegensatz zum Alpenvorland, wo ältere glazifluviale Ablagerungen topographisch höher liegen als jüngere. Die Annahme liegt nahe, dass zwischen diesen beiden Bereichen eine Scharnierzone vorliegt. Diesbezüglich könnten gewisse randliche Zonen des südlichen Oberrheingrabens durchaus für die schrittweise Tieferlegung des mittelländischen Entwässerungssystems verantwortlich sein. Der Rheintalabschnitt zwischen Waldshut-Koblenz und Basel stellt im Umfeld der sich hebenden Alpen (inkl. Mittelland), Jura und Schwarzwald sowie dem sich absenkenden Oberrheingraben eine Schwellenregion dar.

Im Grenzbereich der Deckenschotter der zentralen Nordschweiz zu den in der vorliegenden Arbeit behandelten Ablagerungen sind keine tektonischen Strukturen bekannt, welche mit Sicherheit neotektonische Aktivität aufweisen und eine grundsätzlich andere geomorpholo- gische Entwicklung in den beiden Gebieten zur Folge haben könnten. Südlich der Konfluenz der beiden Entwässerungssysteme, welche wahrscheinlich seit je her im Dreieck Waldshut-Klingnau-Leibstadt lag, wurde für die Mandacher Überschiebung und die Lägernstruktur eine Aktivität während des Quartärs postuliert (GRAF 1993). Vergleichbare Störungen sind im Konfluenzbereich nicht vorhanden. Aus diesem Grund wird davon ausgegangen, dass im Untersuchungsgebiet der vorliegenden Arbeit und der zentralen Nordschweiz eine gleichartige geomorphologische Entwicklung stattgefunden hat.

\subsection{Vergleich mit dem süddeutschen Alpenvorland}

Anders sieht der Vergleich mit den (plio-) pleistozänen Ablagerungen im süddeutschen Alpenvorland aus. Zwar kann von einer im Groben vergleichbaren Hebung des Alpenkörpers ausgegangen werden, aber die dort aktiven Flüsse und Gletschersysteme sind auf das Donau-System ausgerichtet, welches nach $\mathrm{E}$ entwässert. Das heißt, dass das Vorflutniveau des Entwässerungsnetzes - und damit die morphogenetische Entwicklung des Gebietes - von anderen Vorgängen geprägt werden als im Rheinsystem. Somit kann nicht a priori von einer analogen Morphogenese in den beiden Flusssystemen ausgegangen werden, was bedeutet, dass die frühpleistozänen Ablagerungen in beiden Gebieten nicht allein anhand von geomorphologischen Kriterien korreliert werden können.

\subsection{Morphogenetischer Vergleich mit der zentralen Nordschweiz}

Ein morphologisch-lithostratigraphisches Schema der eiszeitlichen Ablagerungen in der zentralen Nordschweiz (Abb. 2, 15) zeigt, dass auf einen Zeitabschnitt, während dem die Ablagerungen verschiedener Vereisungen sich normalstratigraphisch überlagern (Höhere Deckenschotter), eine markante regionale Absenkung des Entwässerungsnetzes folgte. Es entstand ein Talsystem mit relativ breiten Querschnitten, 


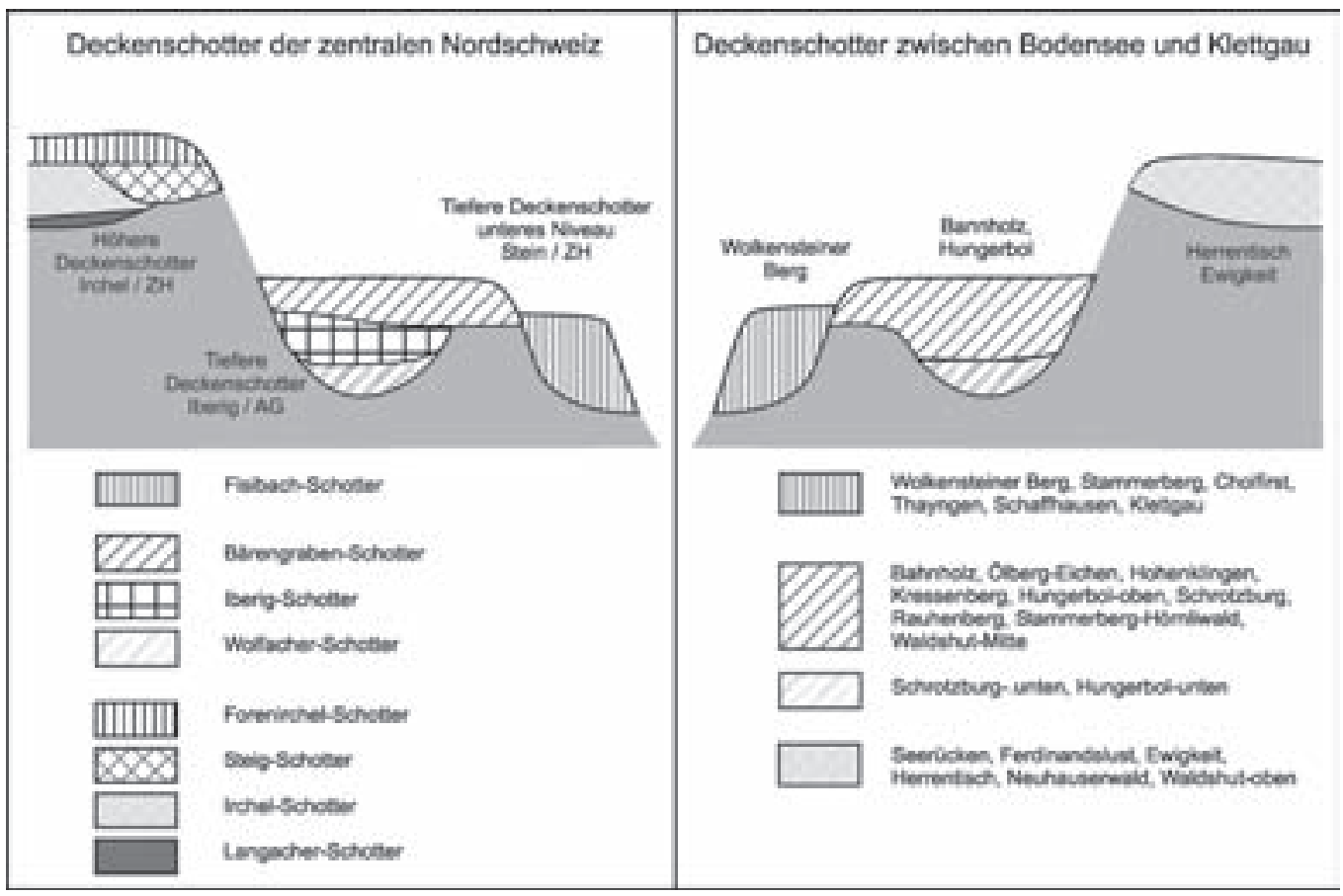

Abb. 15: Geomorphologisch-lithostratigraphische Schemata der Deckenschotter in der zentralen Nordschweiz (nach GRAF 1993, 2000) und der in der vorliegenden Arbeit untersuchten Deckenschotter.

Fig. 15: Schematical comparison of the geomorphology and lithostratigraphy of the Deckenschotter in both northern Switzerland (after GRAF 1993, 2000) and the study area.

in dem sich engere, tiefere Rinnen abzeichnen. Dann wurden erneut Ablagerungen verschiedener Vereisungen aufeinander gestapelt (Tiefere Deckenschotter), wobei zunächst die engen Rinnen aufgeschottert und später die angrenzenden Felsplateaus überschottert wurden. Eine darauf folgende Erosionsphase schuf ein Talsystem, dessen Höhenlage nur wenig tiefer lag als zu Beginn der Entstehung der Tieferen Deckenschotter. Nach einer erneuten Aufschotterung (Tiefere Deckenschotter, unteres Niveau) folgte eine zweite markante Absenkung des regionalen Entwässerungssystems, welche den Übergang zum Komplex der Hoch- und Niederterrassen markiert. Es traten also offenbar Zeitabschnitte auf, während denen keine regionale Absenkung des Entwässerungssystems zwischen den einzelnen Akkumulationsphasen stattfand, was sich in einer normalstratigraphischen Überlagerung von Sedimenten ver- schiedener Vereisungen manifestiert. Zwei Mal traten dann Erosionsphasen auf, welche eine markante Absenkung zur Folge hatten. Demnach hätten sich im Umfeld des rheinwärtigen nordalpinen Gewässernetzes tektonische Ruhephasen mit Aktivitätsphasen abgewechselt. Wo die tektonische Aktivität dabei jeweils stattfand, ob im Bereich der alpinen Hebung oder der oberrheinischen Absenkung (oder an beiden Orten) und welche Rolle dabei das Hochrheingebiet unterhalb von Waldshut (bzw. die vertikalen Relativbewegungen von Jura und Schwarzwald) spielte, ist im Augenblick nicht aufzugliedern.

Wesentlich für den Vergleich der in der vorliegenden Arbeit behandelten Deckenschotter mit denjenigen der zentralen Nordschweiz ist die Gleichartigkeit des Wechsels zwischen Akkumulations- und Erosionsphasen. Auf ein vermutlich wenig gegliedertes regionales Reli- 
ef wurden die Höheren Deckenschotter abgelagert. In der zentralen Nordschweiz sind vier Akkumulationsphasen belegt, im hier behandelten Gebiet nur eine. Es schloss sich eine markante Erosionsphase an, welche das regionale Gewässernetz um rund $100 \mathrm{~m}$ tiefer legte. Diese Erosion mag mehrphasig gewesen sein, denn das anschließend vorliegende Relief wies offenbar relativ enge Täler auf, die von Felsplateaus gesäumt wurden. Anschließend stellte sich wiederum eine Akkumulationsphase ein, welche in der zentralen Nordschweiz drei Phasen und im hier behandelten Untersuchungsgebiet mindestens zwei Phasen umfasste. Dabei wurden zunächst die engen Täler aufgeschottert und in einem späteren Zeitabschnitt auch die angrenzenden Plateaus. Hernach senkte eine Erosionsphase das Gewässernetz wieder $a b$, und zwar bis wenige Meter unterhalb des Niveaus vor der zweiten Akkumulationsphase. Anschließend wurden erneut Sedimente abgelagert, bis schließlich eine zweite markante regionale Absenkung des Gewässernetzes erfolgte, die den Übergang zum Komplex der Hoch- und Niederterrassen markiert.

Die Analogie der Abfolge von Akkumulationen und Erosionsphasen macht eine Gleichzeitigkeit der Ereignisse in beiden Gebieten wahrscheinlich, wenngleich die Anzahl der Ablagerungsphasen in den einzelnen Akkumulationen nach dem heutigen Wissensstand nicht übereinstimmt. Was die Höheren Deckenschotter betrifft, kann die Frage der großräumigen Entwicklung der alpinen Entwässerungsverhältnisse diesbezüglich eine Rolle spielen, indem vielleicht die Entwässerung über die Walensee-Achse das ältere Element ist als diejenige über das heutige St. Galler Rheintal. Demzufolge könnten im hier behandelten Untersuchungsgebiet weniger Ablagerungsphasen aufgetreten sein als im WalenseeRheingletschersystem. Auf diese Frage soll hier aber nicht weiter eingegangen werden; es sei verwiesen auf Graf (1993), HABBE (1994) und VILLINGER (1986, 1998). Selbstverständlich kann die Relikthaftigkeit der Sedimente auch durch spätere Abtragung bedingt sein.

HANTKE (1962) postulierte eine gletscherrandliche Entstehung der Deckenschotter des Boden-
see-Rhein-Gebietes. Sie wären als Abschwemmungen von Gesteinsmaterial auf angrenzende Molassehügel zu deuten, die während der mittel- und spätpleistozänen Vereisungen entstanden. Wie oben erwähnt (Kapitel 5.3.1), kann dies für das Vorkommen von Salen-Reutenen nicht ausgeschlossen werden. Die Verhältnisse am Hungerbol auf dem Schiener Berg zeigen jedoch, dass dieses Gebiet auch während Zeiten ohne Gletscherpräsenz ein Flusssystem aufwies, was klar gegen eine einstige Hügelsituation spricht.

\section{Schlussfolgerungen}

Anhand von geomorphologischen, sedimentologischen und sedimentpetrographischen Untersuchungen wird die Existenz von drei morphostratigraphischen und vier lithostratigraphischen Einheiten in den Deckenschottern zwischen Bodensee und Klettgau postuliert. Die Höheren Deckenschotter bedecken eine nur gering strukturierte Felsoberfläche. Darin eingeschachtelt sind die Tieferen Deckenschotter, welche ein System von Rinnen mit seitlichen Felsplateaus erfüllen. Die Tieferen Deckenschotter, unteres Niveau, liegen in einem jüngeren Rinnensystem, welches in die Tieferen Deckenschotter eingetieft wurde. Es scheinen kaum neotektonische Vorgänge stattgefunden zu haben, welche eine Zufälligkeit der Höhenverteilung der einzelnen Deckenschotterrelikte annehmen ließe. Einzig die östlich der Mindelsee-Verwerfung liegenden Vorkommen könnten eine gewisse relative höhenmäßige Verstellung erfahren haben.

Anhand von grundsätzlichen Überlegungen zur Korrelierbarkeit dieser Ablagerungen mit den Deckenschottern der zentralen Nordschweiz kann eine im Wesentlichen vergleichbare geomorphologische Entwicklung der Entwässerungsnetze beider Gebiete angenommen werden, was eine vorläufige Korrelation der Ablagerungen beider Gebiete ermöglicht. Es liegen allerdings bisher keine Datierungen vor, welche die vorgestellte Gliederung erhärten würden. Eine Korrelation anhand von geomorphologischen Kriterien mit dem süddeutschen 
Alpenvorland ist aus grundsätzlichen Gründen betreffend die Morphogenese der beiden Gebiete nicht möglich.

\section{Dank}

Zunächst sei den Vertretern der Schweizerischen Landesgeologie (Bundesamt für Landestopografie), Dr. C. Beer und Dr. R. Burkhalter, für die Auftragserteilung und die grosse Unterstützung gedankt, die sie den durchgeführten Untersuchungen entgegenbrachten. Danke an Dr. R. Burkhalter für das Verfassen des Abtracts und die Redaktion des Textes. Prof. Dr. C. Schlüchter (Universität Bern) sei dafür gedankt, dass die Proben für die Schwermineraluntersuchungen im Labor der Universität Bern aufbereitet werden konnten. Dank auch an PD Dr. W. Winkler (ETH Zürich) für die Benutzung des Sedimentlabors für die Auszählung der Schwermineralproben. Für spannende Diskussionen per Brief und E-Mail sowie im Feld sei Dr. D. Ellwanger (LGRB), Prof. Dr. A. Schreiner, Dr. E. Villinger (LGRB), Prof. Dr. E. Bibus (Universität Tübingen), Dr. R. Groschopf (LGRB) herzlich gedankt. Danke für gemeinsame Geländebegehungen und Diskussionen im Feld an A. Zaugg (CSD AG, Frauenfeld). Für die Erlaubnis zur Einsichtnahme in amtseigene geologische Dokumente bestens gedankt sei Dr. K. Nyffenegger (AWEL Zürich) und Dr. M. Baumann (AFU Frauenfeld).

\section{Literatur}

Aitchison, J. (1986): The statistical analysis of compositional data. - 416 S.; London (Chapman \& Hall).

BECK, P. (1933): Über das schweizerische und europäische Pliozän und Pleistozän. - Eclogae geol. Helv., 26/2: 335-437.

Birkhäuser, P., Roth, P., Meier, B. \& Naef. H. (2001): 3D-Seismik: Räumliche Erkundung der mesozoischen Sedimentschichten im Zürcher Weinland. - Nagra technische Berichte: 00-03.

Bitterli, T., Graf, H. R., Matousek, F. \& Wanner, M. (2000): Blatt 1050 Zurzach. - Geologischer Atlas Schweiz 1:25.000, Erläuterungen 102: 89 S.; Bundesamt für Wasser und Geologie.
Bolliger, T., Fejfar, O., Graf, H.R. \& Kälin, D. (1996): Vorläufige Mitteilung über Funde von pliozänen Kleinsäugern aus den höheren Deckenschottern des Irchels (Kt. Zürich). - Eclogae geologicae Helvetiae, 89/3: 1043-1048.

BÜCHI \& MÜLLER AG (1982): Standortuntersuchung für Tiefbohrungen im Raum Salen-Reutenen/ TG. - Unveröffentlichtes geologisches Gutachten zuhänden Swissgas Speicher AG, Zürich.

BÜCHI \& MÜLLER AG (1983): Hörnliquellen - Zwischenbericht über die Untersuchungen der Phase I. - Unveröffentlichtes geologisches Gutachten zuhänden Kommission zur Bildung einer Zweckverbandes Wasserversorgung Seerücken West.

BÜCHI \& MÜLLER AG (1999): Grundwasseruntersuchung Thur-Rhein / Cholfirst-Seerücken, Schlussbericht. - Unveröffentlichtes geologisches Gutachten zuhänden Kantone Zürich und Thurgau.

BÜCHI \& MÜlLER AG (2000): Geologischer Atlas der Schweiz 1:25.000, Blatt Steckborn-Kreuzlingen. - Bericht zuhänden geologischer Landesaufnahme.

BüCHI \& Müller AG (2002): Ausscheidung der Schutzzonen für die Quellen Eggenacker-Moserra. - Unveröffentlichtes geologisches Gutachten zuhänden der Gemeinde Mett-Oberschlatt.

BÜCHI \& MÜLlER AG (2003): Naturgefahrenkartierung Bezirk Kreuzlingen und Teilen Homburg, Raperswilen und Müllheim. - Unveröffentlichtes geologisches Gutachten zuhänden Forstamt Kt. Thurgau.

DAVIS, J.C. (1973): Statistics and data analysis in Geology. - 549 S.; New York (Wiley).

Digby, P.G.N. \& Kempton, R.A. (1982): Multivariate analysis of ecological communities. $-206 \mathrm{~S}$; London (Chapman and Hall).

ERB, L. (1934): Erläuterungen zu den Blättern Überlingen und Reichenau (Nachdruck 1989). - 120 S., Geologische Karte 1:25.000 von BadenWürttemberg: $120 \mathrm{~S}$.; Freiburg (Geologisches Landesamt Baden.-Württemberg).

Erb, L., Haus, H.A. \& Rutte, E. (1961): Blatt 8120 Stockach mit Erläuterungen. -Geologische Karte von Baden-Württemberg 1:25.000: 140 S.; Stuttgart (Geologisches Landesamt BadenWürttemberg).

FreI, R. (1912a): Untersuchungen über den Schweizerischen Deckenschotter. - 182 S.; Beitrag geologische Karte Schweiz, N.F. 37.; Bern (Schweizerische Geologische Kommission).

FreI, R. (1912b): Zur Kenntnis des ostschweizerischen Deckenschotters. - Eclogae geoligicae Helvetiae, 11: 814-825. 
FRÜH, J. (1910): Die beiden Deckenschotter auf dem westlichen Seerücken zwischen Untersee und Thurtal. - Mitteilungen thurgische naturforschende Gesellschaft, 19: 3-21.

Gasser, U. \& Nabholz, W. (1969): Zur Sedimentologie der Sandfraktion im Pleistozän des Schweizerischen Mittellandes. - Eclogae geologicae Helvetiae, 62/2: 467-516.

Geiger, E. (1943): Blatt Pfyn-Märstetten-Frauenfeld-Bussnang. - 62 S.; Geologischer Atlas Schweiz 1:25.000, Erläuterungen 16.; Bern (Schweizerische geologische Kommission).

GeIGER, E. (1948): Untersuchungen über den Geröllbestand im Rheingletschergebiet. - Schweizerische Mineralogisch Petrographische Mitteilungen, 28: 274-287.

Geiger, E. (1969): Der Geröllbestand des Rheingeltschergebietes im Raum nördlich von Bodensee und Rhein. - Jahresheft geologisches Landesamt Baden-Württemberg, 11: 127-172.

Graf, H.R. (1993): Die Deckenschotter der Zentralen Nordschweiz. - 151 S.; Dissertation ETH Zürich Nr. 10205 (Zürich).

Graf, H.R. (1996): Caliche-Bildungen auf Höheren Deckenschotter der Nordschweiz? - Eiszeitalter und Gegenwart, 46: 48-53.

Graf, H.R. (2000): Quartärgeologie zwischen Rhein, Thur und Aare (Kantone Aargau, Zürich, Schaffhausen) (Exkursion G am 28. April 2000). - Jahresbericht Mitteilungen oberrheinischer Geologischer Verein, N.F. 82: 113-129.

GraF, H.R. (in Bearbeitung): Mittel- und Spätpleistozän in der Nordschweiz. - Beiträge geologische Karte Schweiz, NF 168; Bern (Schweizerische Geologische Landesaufnahme).

Gutzwiller, A. (1883): Molasse und jüngere Ablagerungen. - In: Gutzwiller, A. \& Schalch, F. (Hrsg.): Geologische Beschreibung der Kantone St. Gallen, Thurgau und Schaffhausen. - Beiträge geologische Karte Schweiz: 19 S.; Bern (Schweizerische Geologische Kommission).

Gutzwiller, A. (1894): Die Dilluvialbildungen der Umgebung von Basel. - Verhandlungen naturforschende Gesellschaft Basel, 10: 576-587.

Habbe, K.A. (1994): Das deutsche Alpenvorland. In: Liedtke, H. \& Marcenik, J. (Hrsg.): Physische Geographie Deutschlands: 440-475; Gotha (Perthes).

Haldimann, P. \& Frey, D. (1991): Aufzeichnungen zur Reflexionsseismik Opalinuston 1991. - Nagra internationale Berichte, Teil 1: 92-32.

HANTKE, R. (1962): Zur Altersfrage des höheren und des tieferen Deckenschotters in der Nordost- schweiz. - Vereinsjahrschrift naturforschende Gesellschaft Zürich, 107/4: 221-232.

Heim, A. (1919): Geologie der Schweiz, Band 1: Molasseland und Juragebirge. - 704 S; Leipzig (Tauchnitz).

Hofmann, F. (1959): Magnetitvorkommen in diluvialen Ablagerungen des Kantons Schaffhausen. Schweizerische Mineralogisch petrographische Mitteilungen, 39: 105-113.

Hofmann, F. (1967a): Südlicher Hegau. - In: HantKe, R., Hofmann, F. \& Suter, H. (Hrsg.): Exkursion Nr. 28, Schaffhausen - Hegau - Stein a. Rh. - Geologischer Führer Schweiz, 6: 491-501.

Hofmann, F. (1967b): Blatt 1052 Andelfingen, Karte und Erläuterungen 52. - 27 S.; Geologischer Atlas Schweiz 1:25.000; Bern (Schweizerische geologische Kommission).

Hofmann, F. (1981): Blatt 1031 Neunkirch, Karte und Erläuterungen 74. - 49 S.; Geologischer Atlas Schweiz 1:25.000; Bern (Schweizerische Geologische Kommission).

Hofmann, F. \& Hantke, R. (1964): Blatt 1032 Diessenhofen, Erläuterungen 38. - 45 S.; Geologischer Atlas Schweiz 1:25.000; Bern (Schweizerische geologische Kommission).

HüBsCher, J. (1961): Blatt 1032 Diessenhofen, Karte 38. - Geologischer Atlas Schweiz 1:25.000; Bern (Schweizerische geologische Kommission).

Hug, J. (1907): Geologie der nördlichen Teile des Kantons Zürich und der angrenzenden Landschaften. - Beiträge geologische Karte Schweiz, N.F. 15.: $127 \mathrm{~S}$.

Krayss, E. \& Keller, O. (1994): Geologie und Landschaftsgeschichte des Murggebietes (Kanton Thurgau). - Mitteilungen thurgische naturforschende Gesellschaft, 52: 7-39.

MBN AG (2004): SN 4.4.6, Umgestaltung Anschluss Schaffhausen-Süd, Galgenbucktunnel, geologischer Bericht zum generellen Projekt. Unveröffentlichtes geologisches Gutachten zuhänden Tiefbauamt Kanton Schaffhausen.

Müller, W.H., NAEF, H. \& GraF, H.R. (2002): Geologische Entwicklung der Nordschweiz, Neotektonik und Langzeitszenarien Zürcher Weinland. - Nagra technische Berichte, 99-08.

NAef, H., BiRkhäuser, P. \& Roth, P. (1995): Interpretation der Reflexiosnseismik im Gebiet nördlich Lägeren - Zürcher Weinland. - Nagra technische Berichte, 94-14.

Penck, A. (1896): Die Glacialbildungen um Schaffhausen und ihre Beziehungen zu den praehistorischen Stationen des Schweizersbildes und von Thayngen. - In: NüEsCH, J. (Hrsg.): Das Schwei- 
zersbild, eine Niederlassung aus palaeolithischer und neolithischer Zeit: 283-308; Zürich (Zürcher \& Furrer).

Penck, A. \& Brückner, E. (1901-1909): Die Alpen im Eiszeitalter, 3 Bd. - 1199 S; Leipzig (Tauchnitz).

Rust, B.R. (1972): Pebble orientation in fluvial gravels. - Journal of sedimentological Petrology, 42/2: 384-388.

Rust, B.R. (1975): Fabric and structure in glaciofluvial gravels. - In: Jopling, A.V. \& McDonald, B.C. (eds.): Glaciofluvial and glaciolacustrine sedimentation. - Special Publication Society econ. Paleontology Mineralogy, 23: 238-248.

Schalch, F. (1883): Das Gebiet nördlich vom Rhein (Kanton Schaffhausen, Höhgau und Schienerberg). - In: Gutzwiller, A. \& Schalch, F. (Hrsg.): Geologische Beschreibung der Kantone St. Gallen, Thurgau und Schaffhausen. Beiträge geologische Karte Schweiz 19; 143 S.; Bern (Schweizerische geologische Kommission).

SchiLl, J. (1859): Geologische Beschreibung der Umgebung von Ueberlingen. - Beiträge Statistik der Inneren Verwaltung Grossherzogthum Baden, 8. Heft: $22 \mathrm{~S}$.

Schreiner, A. (1965): Geologische Aufnahme von Seismikbohrungen auf dem Schiener Berge. - Archiv Landesamt Geologie, Rohstoffe und Bergbau (LRGB) Baden-Württemberg.

Schreiner, A. (1973): Erläuterungen zu Blatt 8219 Singen. - 139 S.; Geologische Karte von BadenWürttemberg 1:25.000; Stuttgart (Geologisches Landesamt Baden-Württemberg).

Schreiner, A. (1983): Erläuterungen zu Blatt 8218 Gottmadingen. - 124 S.; Geologische Karte von Baden-Württemberg 1:25.000; Stuttgart (Geologisches Landesamt Baden-Württemberg).

Schreiner, A. (1991): Deckenschotter im Hegau und am westlichen Bodensee. - 15 S.; Unpubliziertes Manuskript.

Schreiner, A. (1992a): Geologische Karte Hegau und westlicher Bodensee 1:50.000, erweiterte Neuauflage nach Aufnahmen früherer Autoren. - Freiburg (Geologisches Landesamt BadenWürttemberg).
SCHREINER, A. (1992b): Erläuterungen zur geologischen Karte Hegau und westlicher Bodensee 1:50.000 - 290 S.; Freiburg (Geologisches Landesamt Baden-Württemberg).

Schreiner, A. \& Ebel, R. (1981): Quartärgeologische Untersuchungen in der Umgebung von Interglazialvorkommen im östlichen Rheingletschergebiet. - Jahrheft geologisches Landesamt Baden-Württemberg, 31: 183-196.

Szepessy, D. (1999): Untersuchungen zur Geologie im Rheingebiet zwischen Diessenhofen (TG) und Feuerthalen $(\mathrm{ZH}) .-112$ S.; Unpublizierte Diplomarbeit der Universität Zürich.

VERDERBER, R. (1992): Quartärgeologische Untersuchungen im Hochrheingebiet zwischen Schaffhausen und Basel. - 169 S.; Dissertation Universität Freiburg.

Villinger, E. (1986): Untersuchungen zur Flussgeschichte von Aare/Donau und Alpenrhein und zur Entwicklung des Malm-Karsts in Südwestdeutschland. - Jh. geol. Landesamt Bad.-Württemb., 28: 295-362.

VILLINGER, E. (1998): Zur Flussgeschichte von Rhein und Donau in Südwestdeutschland. - Jahrbuch Mitteilungen oberrheinischer geologischer Verein, N.F. 80: 361-398.

Villinger, E. (2003): Zur Paläogeographie von Alpenrhein und oberer Donau - Zeitschrift der deutschen geologischen Gesellschaft 154/2-3: 193-253.

WARD, J. H. (1963): Hierarchical grouping to optimize an objective function. - Journal of the American Statistical Association, 58: 236-244.

ZAUGG, A. (2001): Geologischer Atlas der Schweiz 1:25.000, Blatt 1033 Steckborn - 1034 Kreuzlingen, geologische Aufnahmen der Gebiete südlich des Rheins 1:25.000. - Manuskriptkarte zuhänden der geologischen Landesaufnahme.

ZAUGG, A. (2002): Geologischer Atlas der Schweiz 1:25.000, Blatt 1033 Steckborn - 1034 Kreuzlingen, geologische Aufnahmen des Schiener Bergs - Manuskriptkarte zuhänden der geologischen Landesaufnahme. 


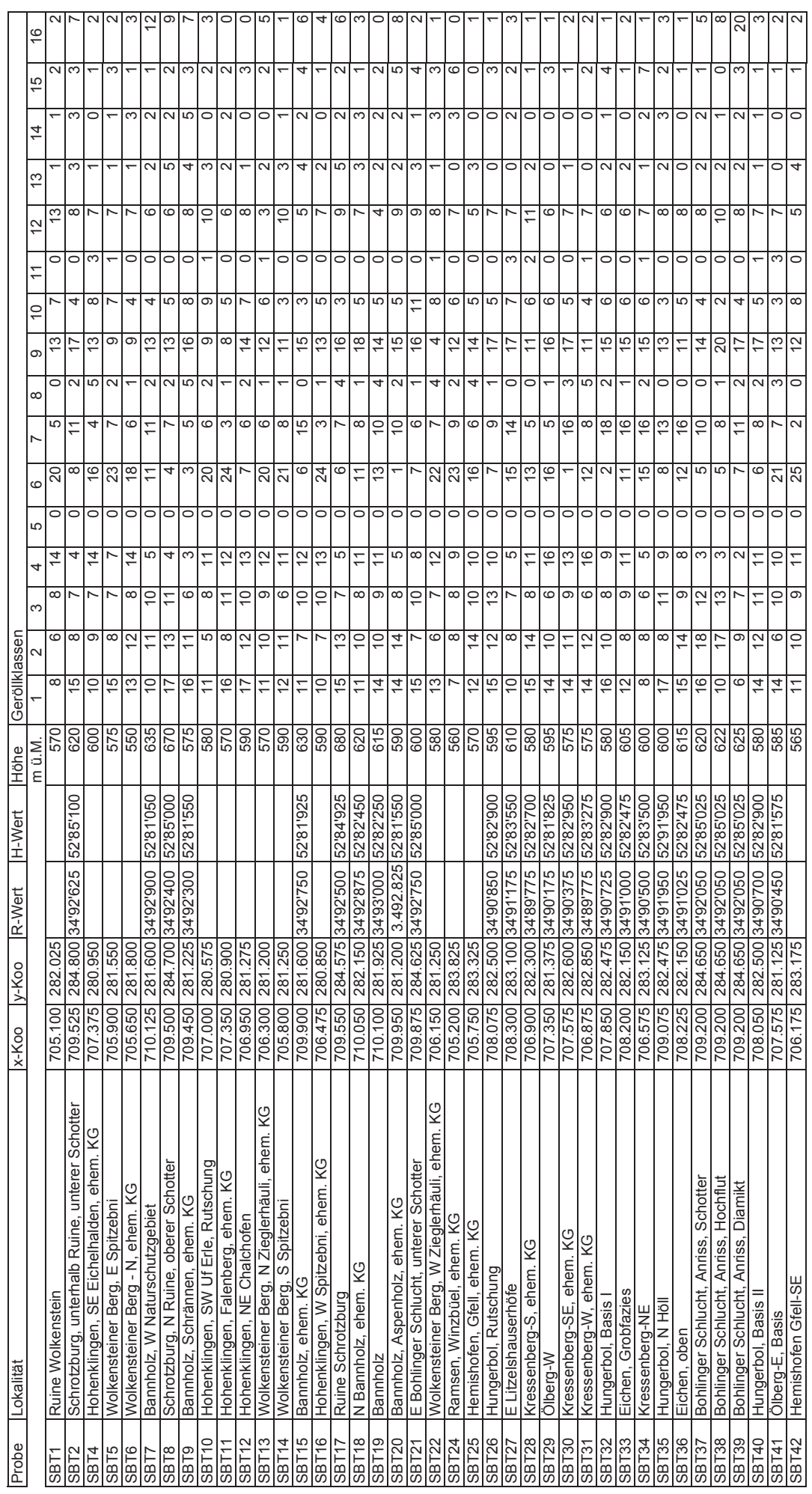




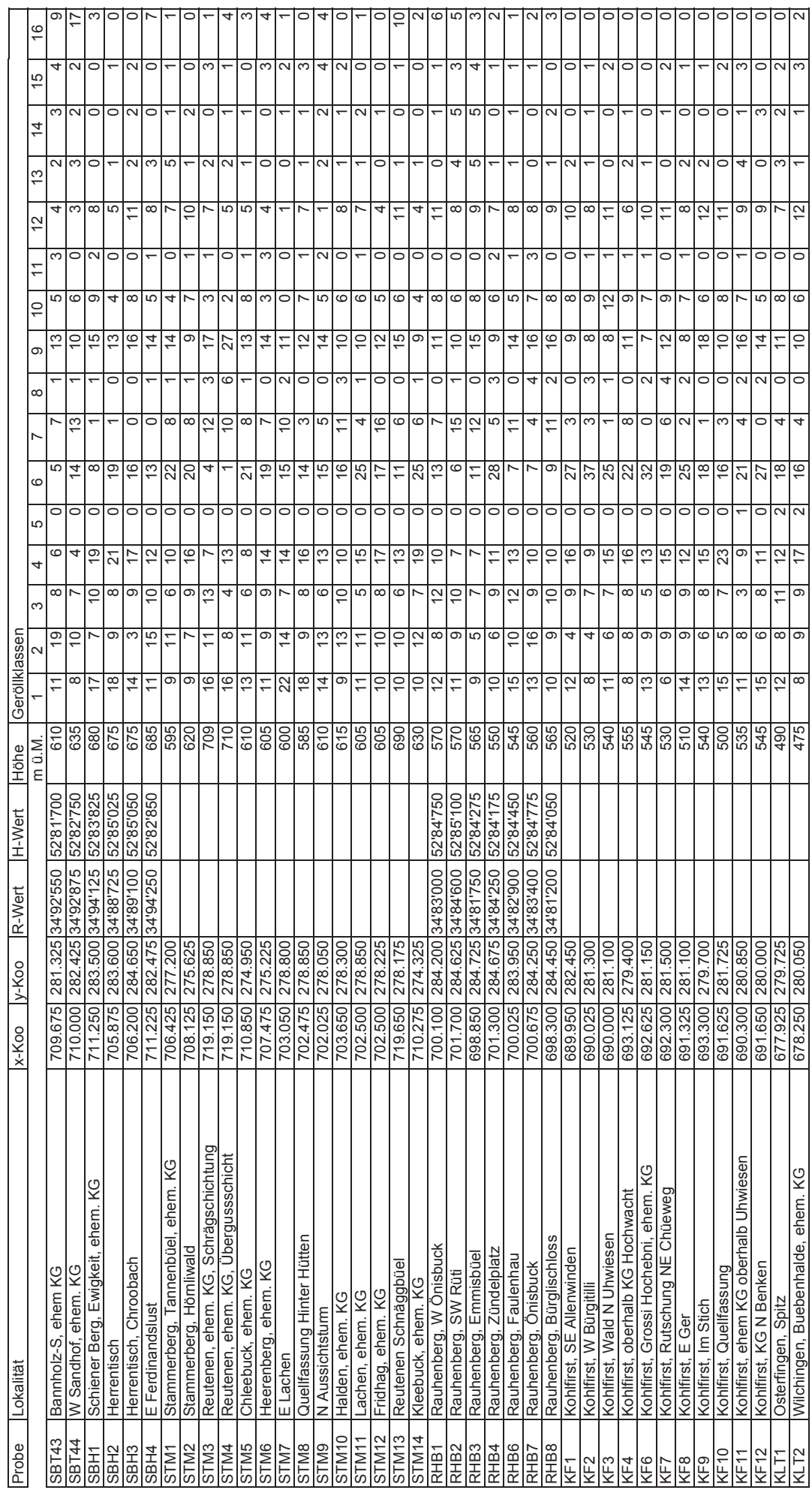




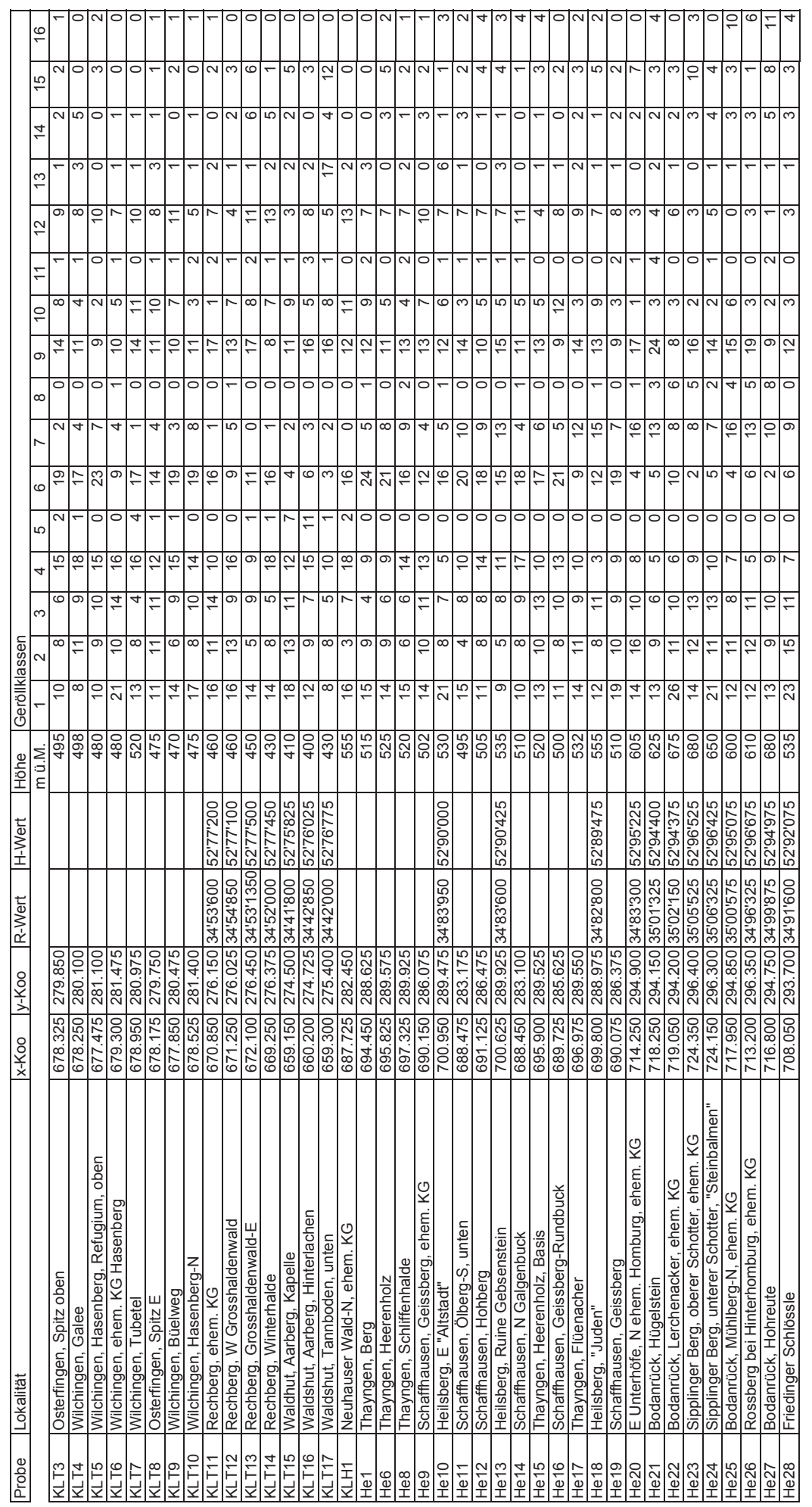




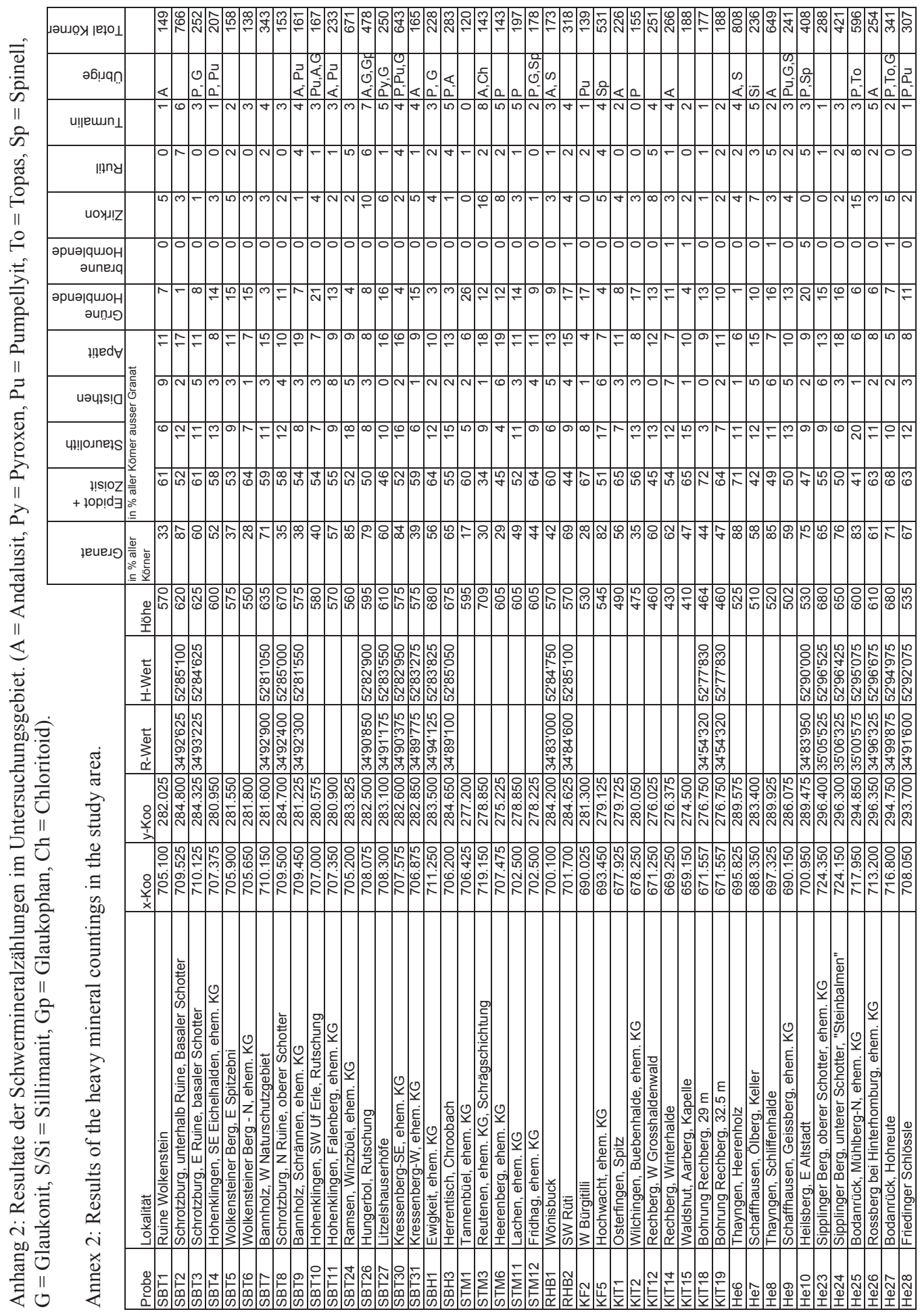


